\title{
DEVELOPMENT OF \\ NONLINEAR HARMONIC SENSORS \\ FOR DETECTION OF MECHANICAL DAMAGE
}

\author{
FINAL REPORT
}

October 1, 2002-December 31, 2003

Prepared by

Alfred E. Crouch

Southwest Research Institute ${ }^{\circledR}$

Post Office Drawer 28510

San Antonio, Texas 78228-0510

Alan Dean, Carl Torres and Jeff Aron

Tuboscope Pipeline Services

P.O. Box 808

Houston, Texas 77001

March 2004

DOE Contract No. DE-FC26-01NT41156

SwRI ${ }^{\circledR}$ Project 14.05030

Prepared for

U.S. Department of Energy

National Energy Technology Laboratory

3610 Collins Ferry Road

Morgantown, West Virginia 26507-0880

SOUTHWEST RESEARCH INSTITUTE

SAN ANTONIO

HOUSTON

DETROIT

WASHINGTON, DC 


\title{
DEVELOPMENT OF NONLINEAR HARMONIC SENSORS FOR DETECTION OF MECHANICAL DAMAGE
}

\author{
FINAL REPORT
}

October 1, 2002-December 31, 2003

\section{Prepared by}

Alfred E. Crouch

Southwest Research Institute $\mathbb{R}$

Post Office Drawer 28510

San Antonio, Texas 78228-0510

Alan Dean, Carl Torres and Jeff Aron

Tuboscope Pipeline Services

P.O. Box 808

Houston, Texas 77001

March 2004

DOE Contract No. DE-FC26-01NT41156

SwRI® Project 14.05030

\section{Prepared for}

U.S. Department of Energy

National Energy Technology Laboratory

3610 Collins Ferry Road

Morgantown, West Virginia 26507-0880

\section{Written by}

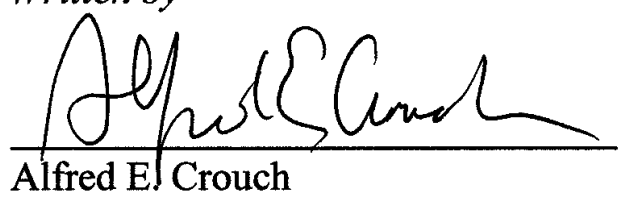

Staff Engineer

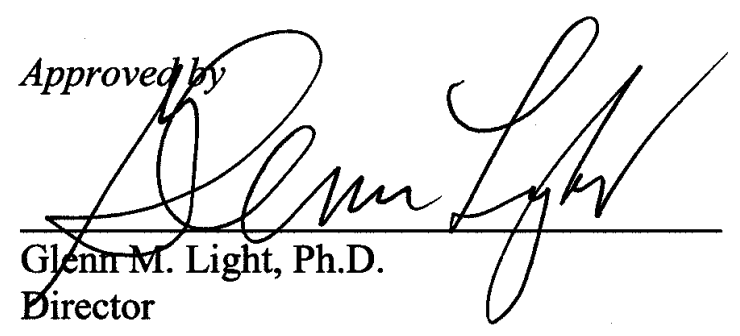




\section{DISCLAIMER}

This report was prepared as an account of work sponsored by an agency of the United States Government. Neither the United States Government nor any agency thereof, nor any of their employees, makes any warranty, express or implied, or assumes any legal liability or responsibility for the accuracy, completeness, or usefulness of any information, apparatus, product, or process disclosed, or represents that its use would not infringe privately owned rights. Reference herein to any specific commercial product, process, or service by trade name, trademark, manufacturer, or otherwise does not necessarily constitute or imply its endorsement, recommendation, or favoring by the United States Government or any agency thereof. The views and opinions of authors expressed herein do not necessarily state or reflect those of the United States Government or any agency thereof.

This Final Report was prepared with the support of the U.S. Department of Energy, under Award No. DE-FC26-02NT41156. However, any opinions, findings, conclusions, or recommendations expressed herein are those of the authors and do not necessarily reflect the views of the DOE. 


\begin{abstract}
In a joint effort with Tuboscope Pipeline Services of Houston, Texas, Southwest Research Institute (SwRI) adapted its nonlinear harmonic (NLH) sensing technology for use on a new in-line inspection system (smart pig). Nonlinear harmonics, an AC magnetic method for detecting local anomalies of stress and plastic deformation, shows promise of improved characterization of mechanical damage defects such as gouged dents, even though the dents may have re-rounded. The SwRI-Tuboscope project produced a sensor design, electronic design, and sensor suspension design that are directly adaptable to a multitechnology ILI system. This report describes the NLH method, the sensor, circuit, and suspension designs, and shows results from the supporting laboratory work.
\end{abstract}




\section{TABLE OF CONTENTS}

$\underline{\text { Page }}$

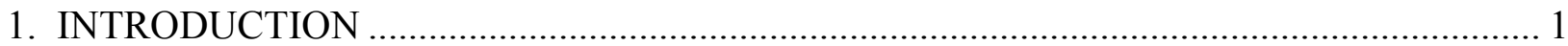

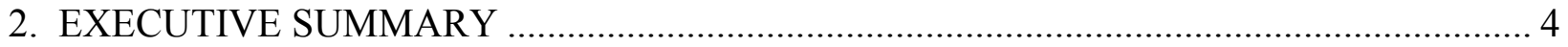

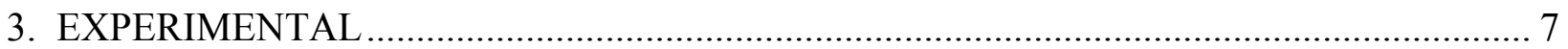

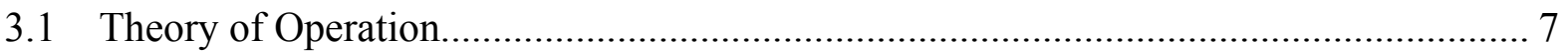

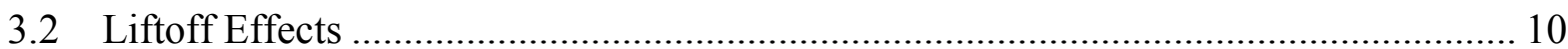

3.2.1 Point Contact Probe ................................................................................ 10

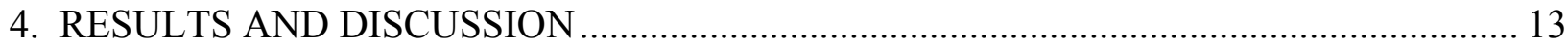

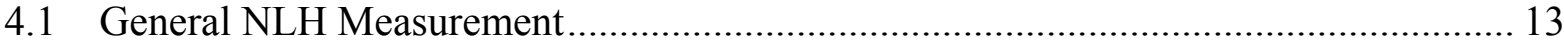

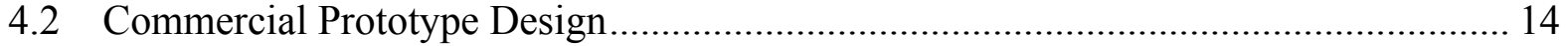

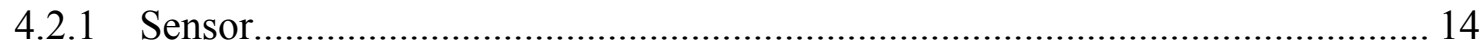

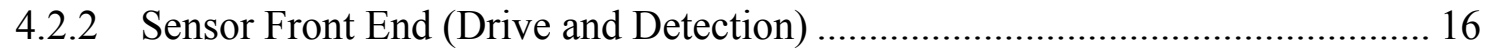

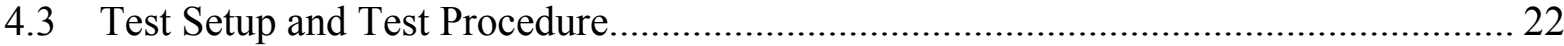

4.4 Prototype Data Analysis .......................................................................................... 26

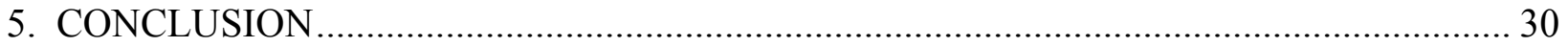

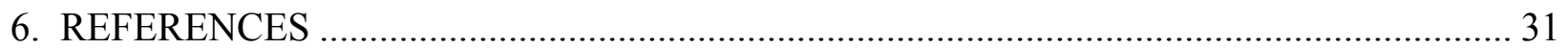




\section{LIST OF FIGURES}

Figure

$\underline{\text { Page }}$

$1 \quad$ Relationship between NLH patterns and defect severity ................................... 3

$2 \quad$ Nonlinear harmonic sensor and associated circuitry .......................................... 7

3 NLH response to mechanical damage defect (gouge) ........................................... 8

$4 \quad$ Effects of applied stress on magnetic hysteresis curves ..................................... 8

$5 \quad$ Effects of plastic deformation on initial magnetic response ................................... 9

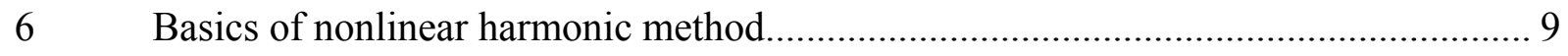

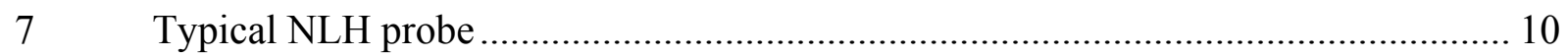

$8 \quad$ NLH probe with single rounded pole for reducing effects of probe tilt ................... 11

$9 \quad$ Tilt response compared to defect response for point-contact probe ........................ 11

10 Standard probe with rounded pole tips to reduce tilt error ................................... 11

11 Tilt and defect response from standard probe with rounded pole tips ..................... 12

12 SwRI NLH system using laboratory equipment ............................................. 13

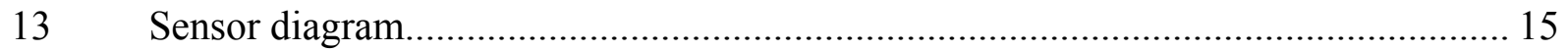

14 Close-up of the encapsulated sensor core and coils .......................................... 15

15 Actual NLH sensors ................................................................................. 16

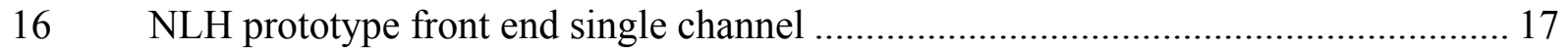

17 Overview of the NLH electronics .................................................................... 17

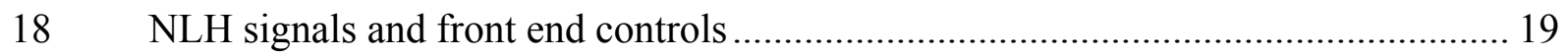

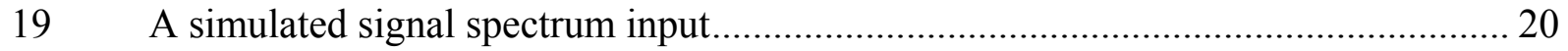

$20 \quad 30 \mathrm{kHz}$ I detector output spectrum (before low-pass filtering) .............................. 20

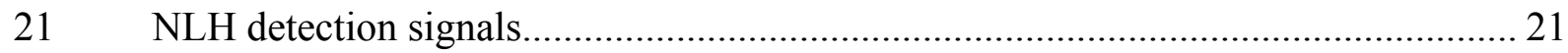

22 Prototype four-sensor NLH system setup for test scanning .................................. 22

23 NLH commercial prototype test system setup ................................................. 23

$24 \quad$ NLH test setup with Linalog $®$ MAX recorder and MUX unit............................... 23

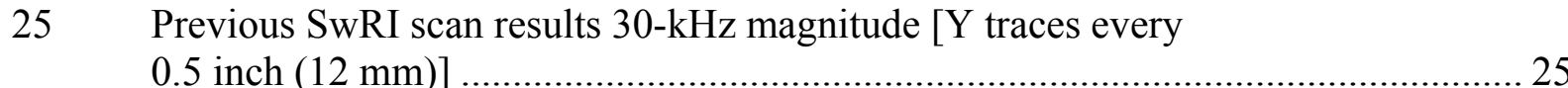




\section{LIST OF FIGURES}

Figure

$\underline{\text { Page }}$

26 Previous SwRI scan results $30-\mathrm{kHz}$ phase [Y traces every

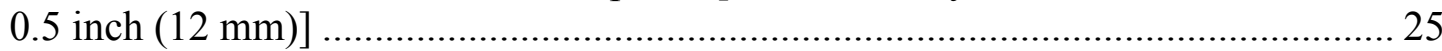

27 Previous SwRI scan results: Waterfall plot of $30-\mathrm{kHz}$ magnitude

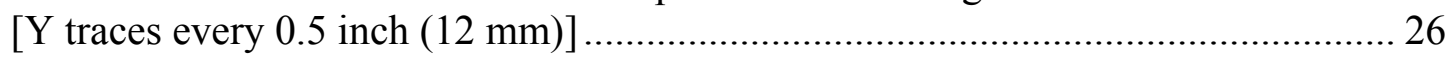

28 Tuboscope LinaView ${ }^{\mathrm{TM}}$ contour scan: $30-\mathrm{kHz}$ magnitude

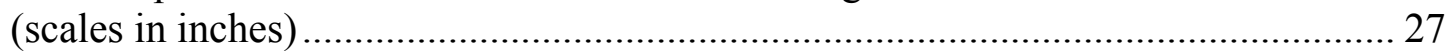

29 Tuboscope LinaView ${ }^{\mathrm{TM}}$ contour scan: $10-\mathrm{kHz}$ magnitude (scales in inches).... 


\section{INTRODUCTION}

This project focused on the reliability and safety of the transmission infrastructure. Mechanical damage (pipe wall deformation) in gas transmission pipelines most often occurs as a result of either impingement of a hard surface (such as a rock) against the pipe or contact against the pipe by construction equipment such as a backhoe or a boring tool. The damage can be a simple dent (common with rock impingement) or a gouged dent or a gouge without denting. In some cases, gouged dents are re-rounded by the pipeline's internal pressure so that the only visible damage remaining is the gouge [1].

For many years, vendors have been offering in-line inspection (ILI) capability for detection of dents. The geometry pig - or caliper pig, as it is sometimes called — can be pumped through the pipeline to detect, measure, and pinpoint the location of pipe wall distortions such as dents and pipe ovality. The T. D. Williamson Kaliper ${ }^{\circledR}$ pig was one of the first such pigs offered to the pipeline operator. This pig, as do most other geometry pigs, uses spring-loaded feelers to track the inner surface of the pipeline and record deviations in pipe radius. These radius changes can be interpreted in terms of dent depth or amount of out-of-roundness. Geometry pigs also carry odometer wheels or some equivalent method of determining defect axial location in the pipe.

In general, geometry pigs do an acceptable job of dent detection and measurement. They do not however, discriminate between gouged dents and smooth dents. This discrimination is important because of the relative severity of those two types of defects for potential pipeline failure. A smooth rock dent, especially a constrained one, it not likely to lead to a pipeline leak or rupture. A gouged dent, on the other hand, often leads to crack initiation at the gouge edges and subsequent failure after accumulated cyclic loading. An inspection with a geometry pig may detect and locate many pipe wall deformations (dents) but will give no guidance, other than dent depth, for which ones should be repaired and which can be left in the pipe. What has been needed is a sensing technology capable, in one pass, of both detecting and measuring the severity of gouged dents. The nonlinear harmonic (NLH) sensing method has been shown, in previous work, to offer that range of capabilities. By responding to the pattern of stresses on the pipe inner surface, NLH can reveal which defects contain gouges and some idea of the severity of the gouges. Even dents that have been re-rounded leave a telltale stress pattern on the pipe inner surface.

The goal of this project was to develop a field-deployable design of NLH sensors and electronics that could be included in a multifunction smart pig for detecting and evaluating mechanical damage in pipelines. The challenges included the basic NLH probe design, the probe suspension system that would work to keep the probe in intimate contact with the pipe surface in the region of the dent, and electronics that could excite multiple probes with a chosen fundamental frequency and then acquire data of the harmonic amplitude, phase, and other selected parameters.

This report includes the relevant laboratory experiments and the resulting mechanical and electronic design. The field-level design was carried out at Tuboscope Pipeline Services, a Varco Company, in Houston, Texas. Tuboscope created the in-line corrosion inspection business with their Linalog ${ }^{\circledR}$ series of smart pigs in the mid-1960s and remains one of the leading vendors of ILI services. 
Southwest Research Institute (SwRI) has an extensive background in the application of magnetic test methods to detect corrosion, cracks and other defects. SwRI has applied the nonlinear harmonic method to many steel products including railroad rails, plates, and pipes. In one successful project [2], SwRI was involved with NLH scanning of gouged dents in 24-inch pipe specimens while the pipes were pressurized with water. Ultimate pressure testing to failure demonstrated a correlation between the NLH signal patterns and the severity of the mechanical damage defect.

\section{The completed work relates to Gas Infrastructure Reliability}

The stated objective of the NETL Gas Infrastructure Reliability program is to develop technology that will place the necessary tools into the hands of those who maintain and enhance the integrity and operational reliability of the nation's gas transmission and distribution network. This project has produced just such a tool. The NLH sensor/electronics design is intended for direct application on a multipurpose smart pig to be run in operating pipelines.

\section{Data to support the technology claims}

The previous related project demonstrated that NLH could be used to determine the severity of mechanical damage defects, specifically, gouged dents. Figure 1 shows the response of an NLH sensor to a range of mechanical damage defects.

\section{Improvements over existing technologies}

Existing technologies for detecting and measuring pipeline mechanical damage concentrate on the dent only and do not adequately cover gouge measurement. Furthermore, they do not handle the case of the re-rounded dent. The developed technology promises to be responsive to the gouge and easily deployable on an ILI smart pig.

\section{Benefits of completed work}

Prior to this development, there was no design for making nondestructive measurements of mechanical damage severity with an in-line inspection system. This project produced a system that can be added directly to an operating Linalog smart pig. 


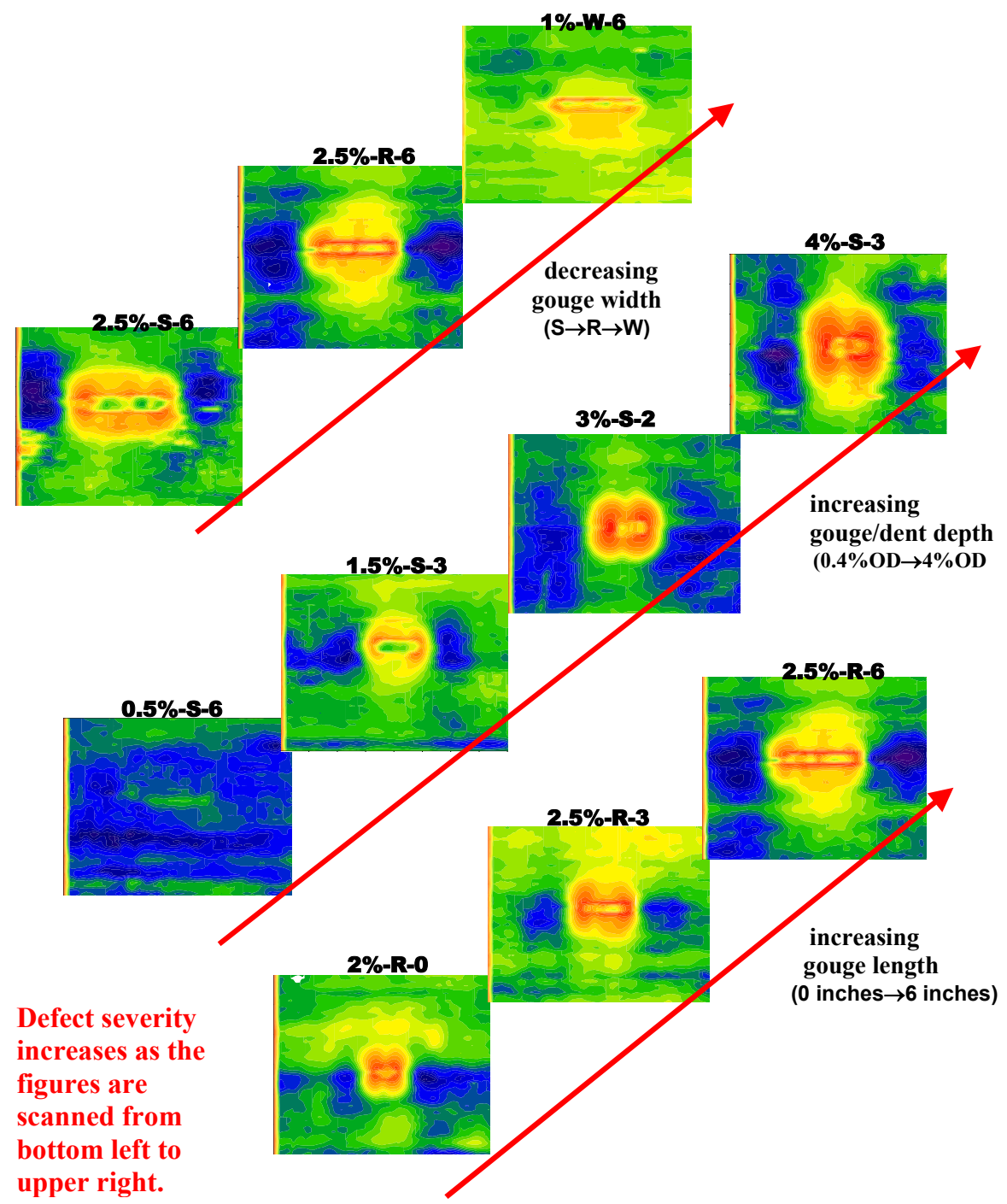

Figure 1. Relationship between NLH patterns and defect severity 


\section{EXECUTIVE SUMMARY}

Mechanical damage (pipe wall deformation) in gas transmission pipelines most often occurs as a result of either impingement of a hard surface (such as a rock) against the pipe or contact against the pipe by construction equipment such as a backhoe or a boring tool. The damage can be a simple dent (common with rock impingement) or a gouged dent or a gouge without denting. In some cases, gouged dents are re-rounded by the pipeline's internal pressure so that the only visible damage remaining is the gouge.

For many years, vendors have been offering ILI capability for detection of dents. The geometry pig - or caliper pig, as it is sometimes called — can be pumped through the pipeline to detect, measure, and pinpoint the location of pipe wall distortions such as dents and pipe ovality. The T. D. Williamson Kaliper ${ }^{\circledR}$ pig was one of the first such pigs offered to the pipeline operator. This pig, as do most other geometry pigs, uses spring-loaded feelers to track the inner surface of the pipeline and record deviations in pipe radius. These radius changes can be interpreted in terms of dent depth or amount of out-of-roundness. Geometry pigs also carry odometer wheels or some equivalent method of determining defect axial location in the pipe.

In general, geometry pigs do an acceptable job of dent detection and measurement. They do not, however, discriminate between gouged dents and smooth dents. This discrimination is important because of the relative severity of those two types of defect for potential pipeline failure. A smooth rock dent, especially a constrained one, is not likely to lead to a pipeline leak or rupture. A gouged dent, on the other hand, often leads to crack initiation at the gouge edges and subsequent failure after accumulated cyclic loading. An inspection with a geometry pig may detect and locate many pipe wall deformations (dents) but will give no guidance, other than dent depth, for which ones should be repaired and which can be left in the pipe. What has been needed is a sensing technology capable, in one pass, of both detecting and measuring the severity of gouged dents. The nonlinear harmonic (NLH) sensing method has been shown, in previous work, to offer that range of capabilities. By responding to the pattern of stresses on the pipe inner surface, NLH can reveal which defects contain gouges and some idea of the severity of the gouge. Even dents that have been re-rounded leave a telltale stress pattern on the pipe inner surface.

The goal of this project was to develop a field-deployable design of NLH sensors and electronics that could be included in a multifunction smart pig for detecting and evaluating mechanical damage in pipelines. The challenges included the basic NLH probe design, the probe suspension system that would work to keep the probe in intimate contact with the pipe surface in the region of the dent and electronics that could excite multiple probes with a chosen fundamental frequency and then acquire data of the harmonic amplitude, phase, and other selected parameters.

This report includes the relevant laboratory experiments and the resulting mechanical and electronic design. The field-level design was carried out at Tuboscope Pipeline Services, a Varco Company, in Houston, Texas. Tuboscope created the in-line corrosion inspection business with their Linalog ${ }^{\circledR}$ series of smart pigs in the mid-1960s and remains one of the leading vendors of ILI services. 
This project included five tasks as follows.

\section{Task 1-Research Management Plan}

A work breakdown structure and supporting narrative that concisely addressed the overall project was developed. The plan included a summary of the technical objectives and technical approach for each task and, where appropriate, for each subtask. Also included were detailed schedules and planned expenditures for each task and all major milestones and decision points.

\section{Task 2-Technology Status Assessment}

SwRI prepared and submitted a report describing the current state of the art of the technology being developed. We described existing technologies and positive and negative aspects of using this technology.

\section{Task 3-Design and Evaluate New NLH Sensors}

Subtask 3.1-Review Relevant NLH Data: Conducted a thorough review of prior DOT work on mechanical damage defect detection projects to identify the investigations and results that have bearing on the requirements of applying NLH technology to a Tuboscope Pipeline Services (TPS) ILI tool.

Subtask 3.2-Investigate Alternative Sensor Design: SwRI performed analytical and experimental work to determine if air-core coils or bulk magnetization provide sufficient sensitivity and defect characterization to be used in an in-line inspection device.

Subtask 3.3-Design Optimum Sensor Array with Field Realism: TPS selected the design parameters for the sensor array to be used on the in-line inspection tool. These parameters included the number of sensors, spacing, orientation, suspension, and cabling.

Subtask 3.4-Evaluate New Sensor on Defect Set at SwRI: SwRI evaluated the new sensor design by scanning mechanical damage defects on hand in SwRI laboratories. These defects consisted of a range of dents and gouges that have been previously examined with earlier NLH sensors.

Subtask 3.5-Fabricate Prototype Sensors: Three prototype sensors were fabricated for use by TPS in producing a production sensor design. TPS used the prototype sensors to establish the operating characteristics of their inspection system.

\section{Task 4-Design, Fabricate, and Test Production Sensors}

Subtask 4.1-Design Sensors for Production: TPS completed the production design for the NLH sensors. This included mechanical suspension linkage and environmental protection, including wear-resistant inserts.

\section{Task 5-Design, Fabricate, and Evaluate Electronics}

Subtask 5.1-System Design Review at Tuboscope: SwRI staff collaborated with TPS staff at the TPS facility for familiarization with the overall design philosophy of the new in-line inspection tool of which NLH technology is only one part. This was to assure that the NLH subsystem was consistent in mechanical, electronic, and magnetic design with the rest of the total system. 
Subtask 5.2-Design Electronic Circuitry: TPS designed the excitation and detection circuitry for implementing NLH on the TPS in-line inspection tool.

Subtask 5.3-Design Production Electronics: Multichannel implementation of the TPS electronics was designed in a form factor within the allowable space envelope of the pig's electronics package.

Subtask 5.4-Fabricate and Check Out Electronics: TPS fabricated four sets of NLH electronics hardware.

\section{Task 6-Modify and Test Display Software}

Subtask 6.1-Modify Lina-View to Display Data in Meaningful Format: TPS software engineers modified their standard data display system to show NLH signals in such a way that pipeline integrity decisions could be made for detected mechanical damage.

\section{Task 7-System Integration and Test}

Subtask 7.1-System Integration: The TPS project team combined all the components of the inline inspection tool into a functioning unit in the laboratory. Measurements were made to identify and resolve any issues of critical timing or interference between the various subsystems.

Subtask 7.2-System Test in Tuboscope High Bay: The in-line inspection functions were exercised in a bench test. Operation simulating in-line inspection was carried out with simulated defect signals while being monitored with laboratory instruments to verify proper data flow.

\section{Task 8-General Project Management Activities}

Subtask 8.1-Orientation Training for Tuboscope and SwRI Staff: Early in the project timeline, key TPS staff members traveled to SwRI to attend an orientation session conducted by SwRI staff. This orientation session covered the basics of NLH theory, design, and operation. This training session also included presentations by TPS staff to bring the SwRI team up to date on critical pig design.

Subtask 8.2-Transfer Sensor Fabrication Technology: Once the NLH sensor design had been finalized and the SwRI prototype sensors fabricated, SwRI staff transferred design information to the production sensor fabrication team This included such topics as the coil winding procedure, lead attachment, encapsulation, and wear protection. 


\section{EXPERIMENTAL}

Preceding work with NLH at SwRI [3] showed that NLH could be used to gain quantitative information about the severity of mechanical damage defects (gouged dents). This project produced prototype hardware that makes it possible to add the NLH method to an ILI smart pig. This section describes the supporting laboratory work and the testing that validated the design.

\subsection{Theory of Operation}

The nonlinear harmonics method is an approach that uses a time-varying magnetic field to sense the magnetic properties (e.g. permeability) of a component. This method is based on applying an alternating sinusoidal magnetic field at a given frequency. Because of magnetic hysteresis and nonlinear permeability of ferromagnetic material, the magnetic induction on the material becomes distorted. The distorted magnetic induction waveform contains odd harmonic frequentcies of the applied magnetic field. With the nonlinear harmonics method, these harmonic frequencies are detected and their amplitudes are related to the magnetic condition of the material under test.

The nonlinear harmonics method is typically implemented with an arrangement such as that shown in Figure 2. The magnetic field is applied to the component with an excitation coil, and the resulting magnetic induction is measured with a magnetic field sensor such as a sensing coil. A sinusoidal current of a given frequency is supplied to the excitation coil using an oscillator and power amplifier. The sensor output is amplified and the harmonic frequency content, typically the third harmonic, is determined using a spectrum analyzer or lock-in amplifier referenced to the driving waveform. Simpler configurations, such as bandpass filtering the third harmonic frequency and detecting the output, could also be used. The nonlinear harmonics method has been applied to measurement of stresses in ferromagnetic material by measuring the stress-related changes in the magnetic material.

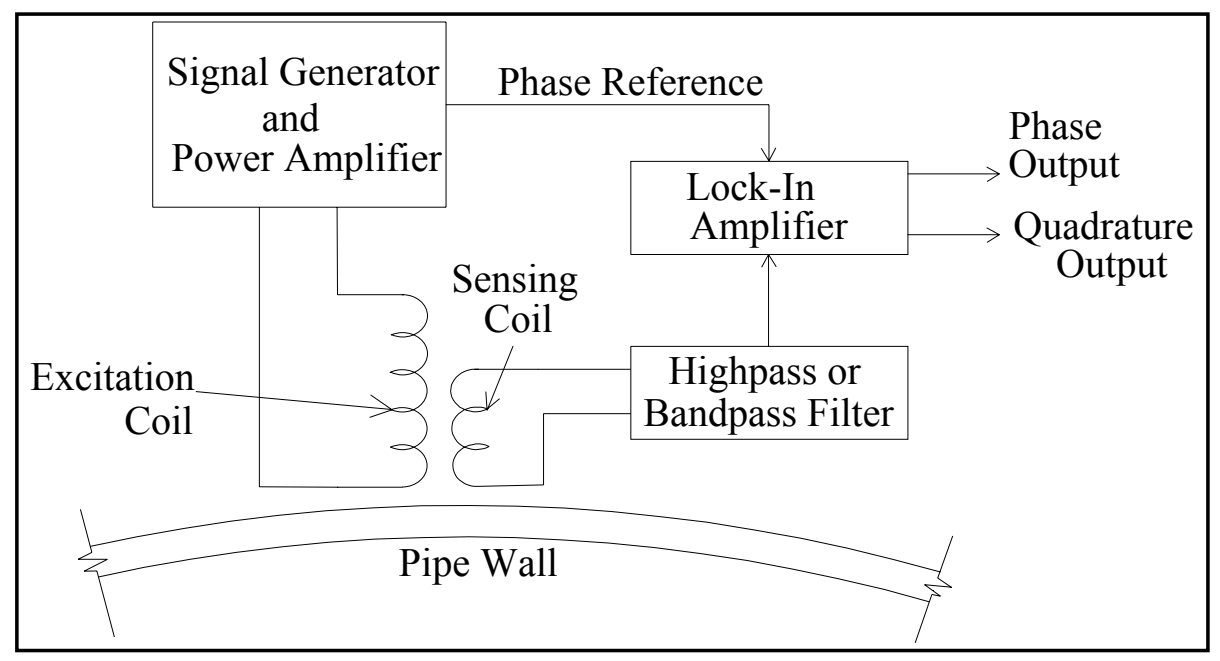

Figure 2. Nonlinear harmonic sensor and associated circuitry 
Since dents and gouges represent pipe wall regions where the magnetic properties have changed, it is anticipated that those regions will produce an NLH response. In fact, laboratory experiments of this technique have demonstrated a clear NLH response to denting and gouging [4]. Figure 3 shows NLH data taken from a mechanically damaged specimen.

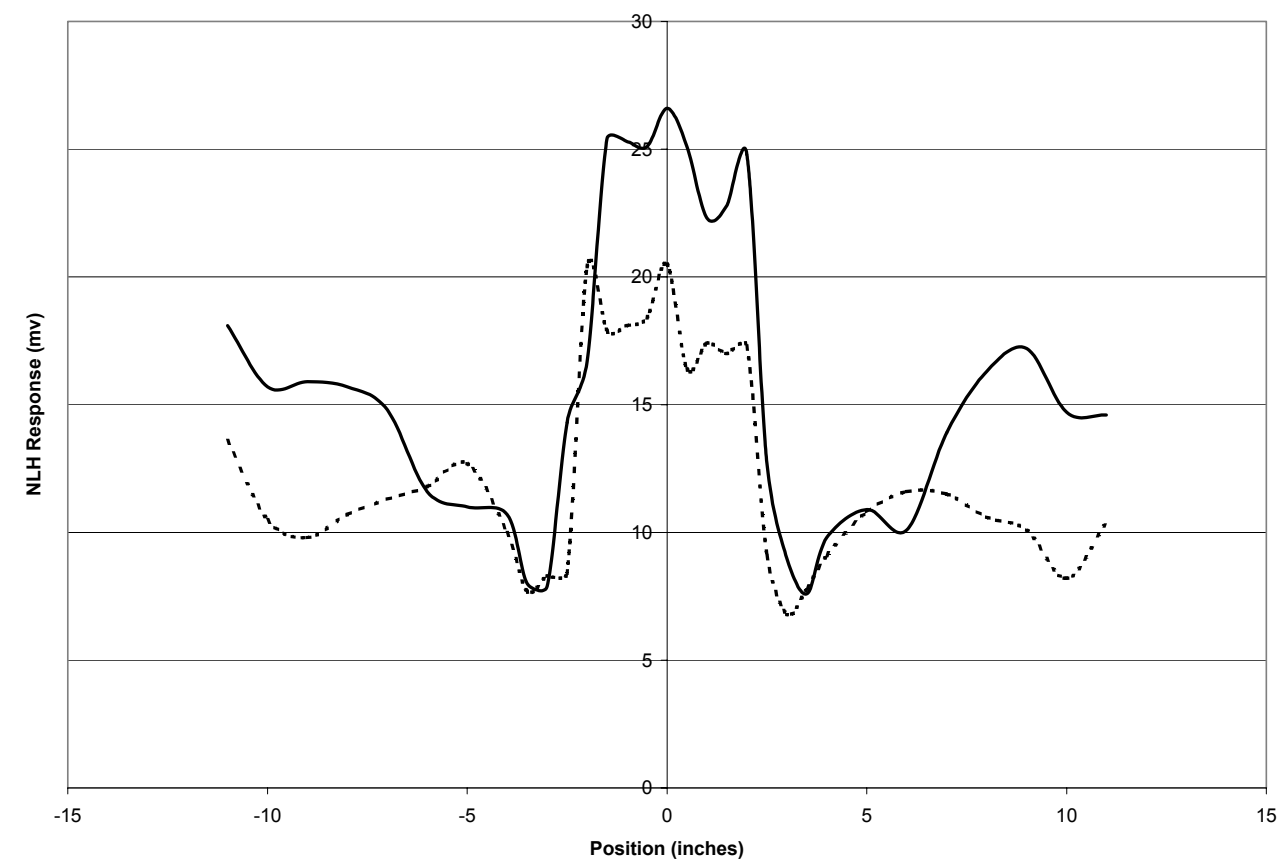

Figure 3. NLH response to mechanical damage defect (gouge)

NLH measures the changes in material magnetic properties as effects of stress and strain. Figure 4 illustrates the effects of applied stress on typical magnetic hysteresis curves. Note that tensile loading causes the curves to be steeper (increased magnetic permeability), while compressive loading yields an opposite result. The corresponding effects of plastic strain on the initial magnetization curves are shown in Figure 5. Note that the effects of compressive plastic strain are similar to applied tensile strain, i.e. an increased magnetic permeability.

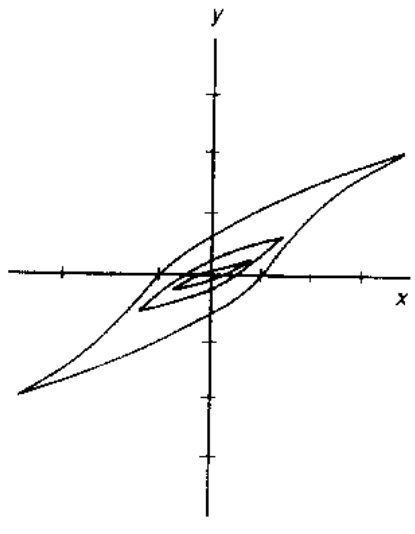

-275 MPa

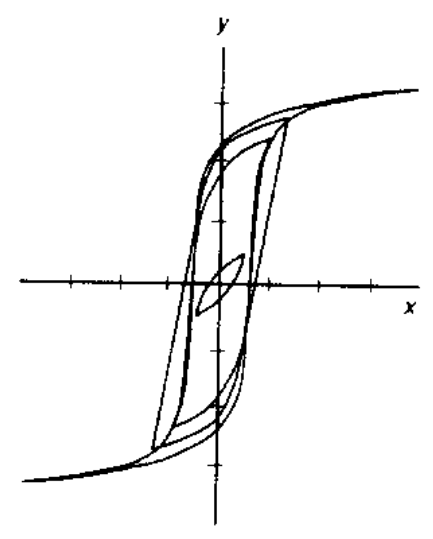

$0 \mathrm{MPa}$

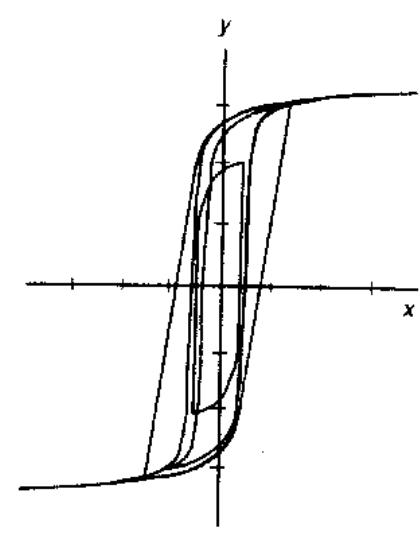

$+275 \mathrm{MPa}$

Figure 4. Effects of applied stress on magnetic hysteresis curves 


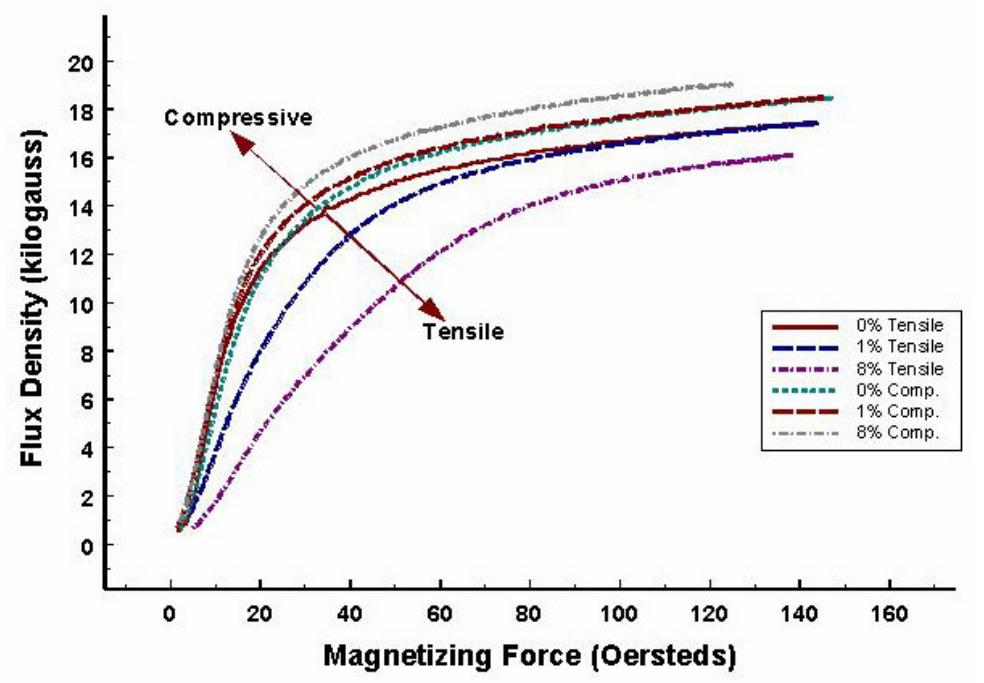

Figure 5. Effects of plastic deformation on initial magnetic response

Figure 6 shows the basis of the NLH method. If an oscillatory magnetic field is impressed on a ferromagnetic workpiece, the magnetic field that is induced into the part is shaped by the hysteresis curve of the material. Since that curve is not linear, the magnetic induction is not a single-frequency sinusoid like the excitation waveform, but rather contains higher frequencies (harmonics) of the excitation frequency. Of particular interest are the odd harmonics, specifically the third. It has been shown in previous work at SwRI that the amplitude and phase of the third harmonic contain information about the amount of biaxial stress in the material.

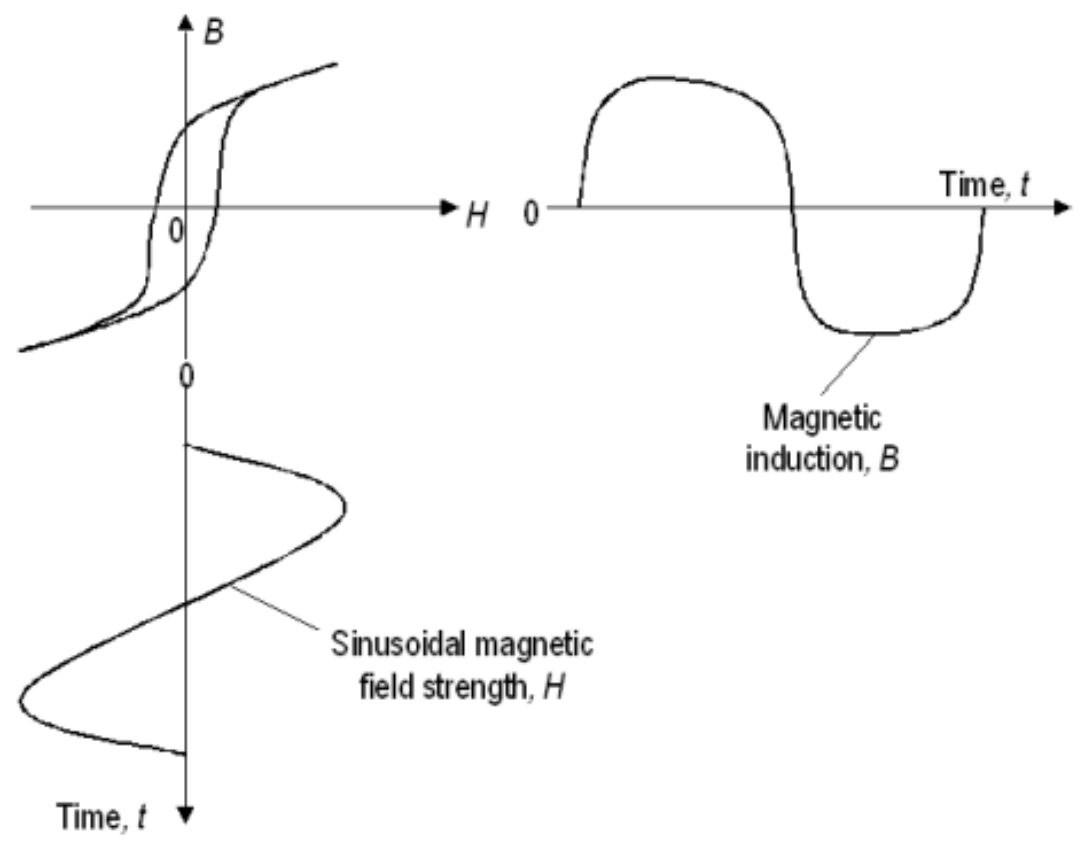

Figure 6. Basics of nonlinear harmonic method 
The NLH probe is essentially a small ferrite-core transformer. When the core is placed against a ferromagnetic material, the material forms part of the transformer's magnetic circuit. Thus, the output of the transformer depends on the magnetic properties of the tested part. An NLH probe, used by SwRI in research on mechanical damage defects, is shown in Figure 7. Note that two windings are wound on the single $\mathrm{C}$-shaped core. The required electronics are relatively simple, as shown in Figure 2. Since the sensing of magnetic properties takes place at $30 \mathrm{kHz}$, the sensing depth into the material is limited to a small fraction of a millimeter. Thus, an in-line inspection for outside mechanical damage relies on there being an effect at the inner surface.

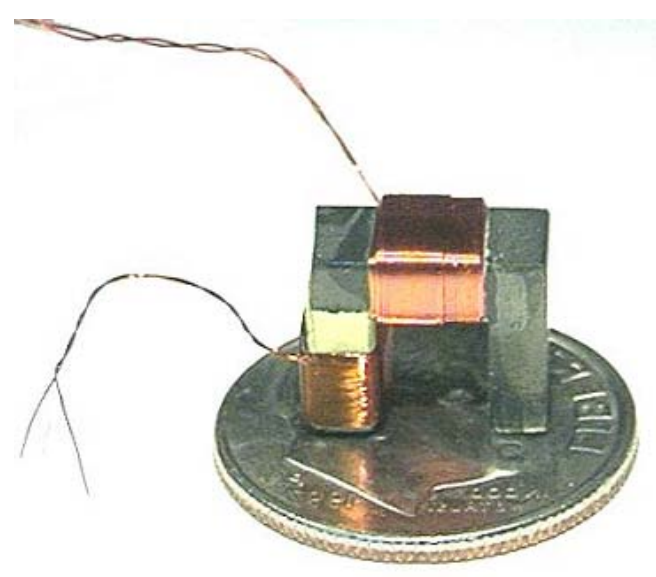

Figure 7. Typical NLH probe

\subsection{Liftoff Effects}

Because the NLH probe has a magnetically permeable core and the pipe wall is also a permeable material, the total reluctance of the probe's magnetic circuit is relatively low when the probe is in contact with the pipe surface. When surface contact is broken, however, and an air gap introduced, the reluctance increases quickly, with a resulting decrease in the probe's sensitivity. Because of this behavior, considerable effort has been put into reducing the likelihood of liftoff and compensating for its effect when it happens. Several attempts to make a probe with reduced liftoff effect are described in the following subsections.

\subsubsection{Point Contact Probe}

Liftoff most often occurs when the probe must follow a curved surface such as the inner surface of a dent. It is relatively easy to keep one pole of the C-core on the surface, but the other will lift off when the pipe curvature is too great and the probe tilts. One solution would be to use a probe with only one pole. An example is shown in Figure 8.

The experiments to determine the immunity to tilt effects were to evaluate candidate probe designs in terms of their sensitivity to tilt off the normal to the pipe surface. It was required that the tilt signal be small compared to the signal from a defect. To compare, a dented plate was used for a defect and the probes were scanned across the defect and tilted off the ideal 90-degree position. The rounded-tip probe with single point contact shown in Figure 8 gave the response shown in Figure 9. 


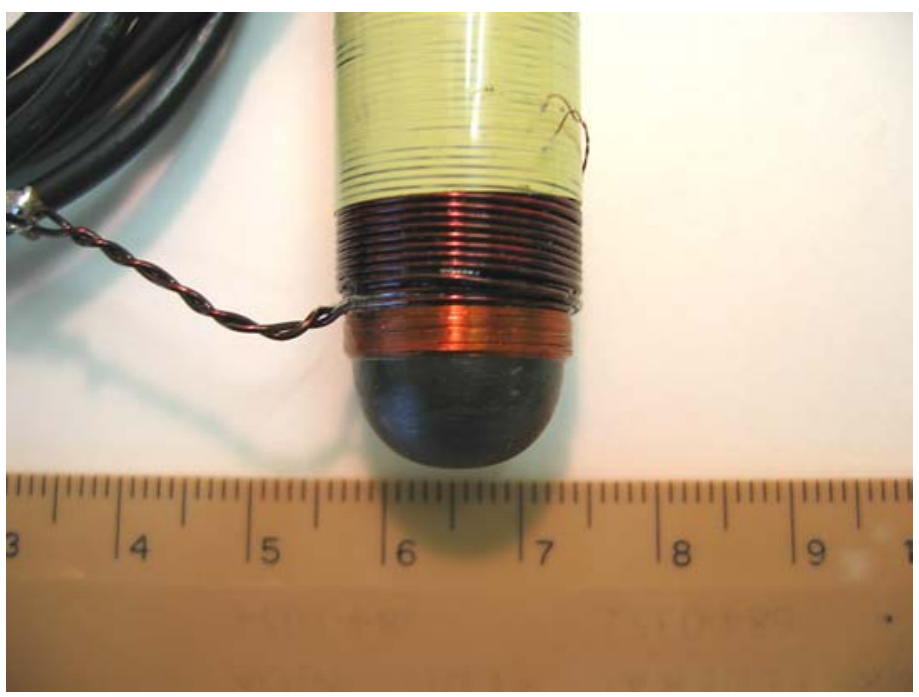

Figure 8. NLH probe with single rounded pole for reducing effects of probe tilt

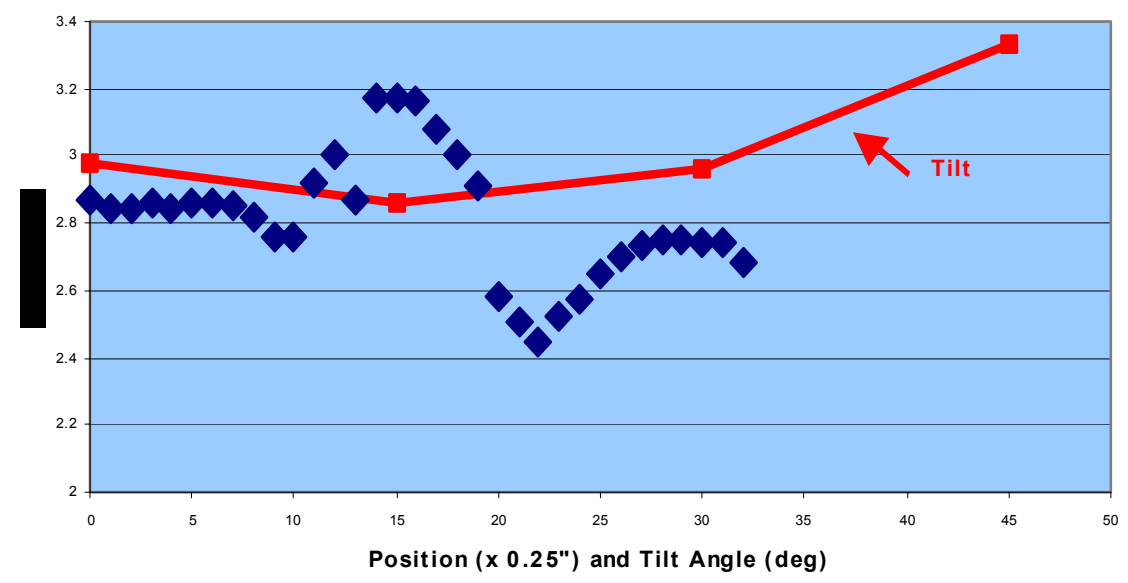

Figure 9. Tilt response compared to defect response for point-contact probe

This was considered unsatisfactory. An alternative design used a standard probe with rounded tips, as shown in Figure 10.
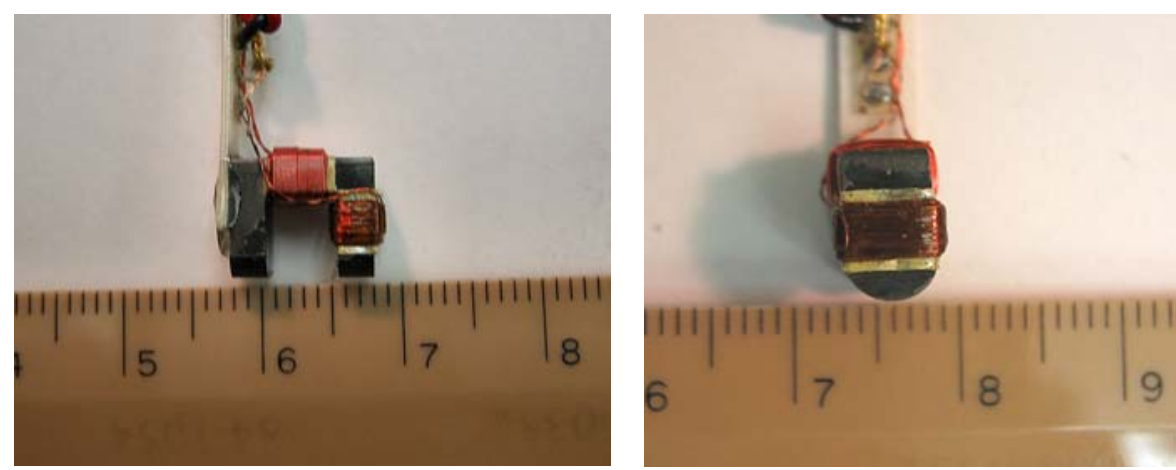

Figure 10. Standard probe with rounded pole tips to reduce tilt error 
The rounded tips reduced the tilt effects to a tolerable level, as shown in the graph of Figure 11.

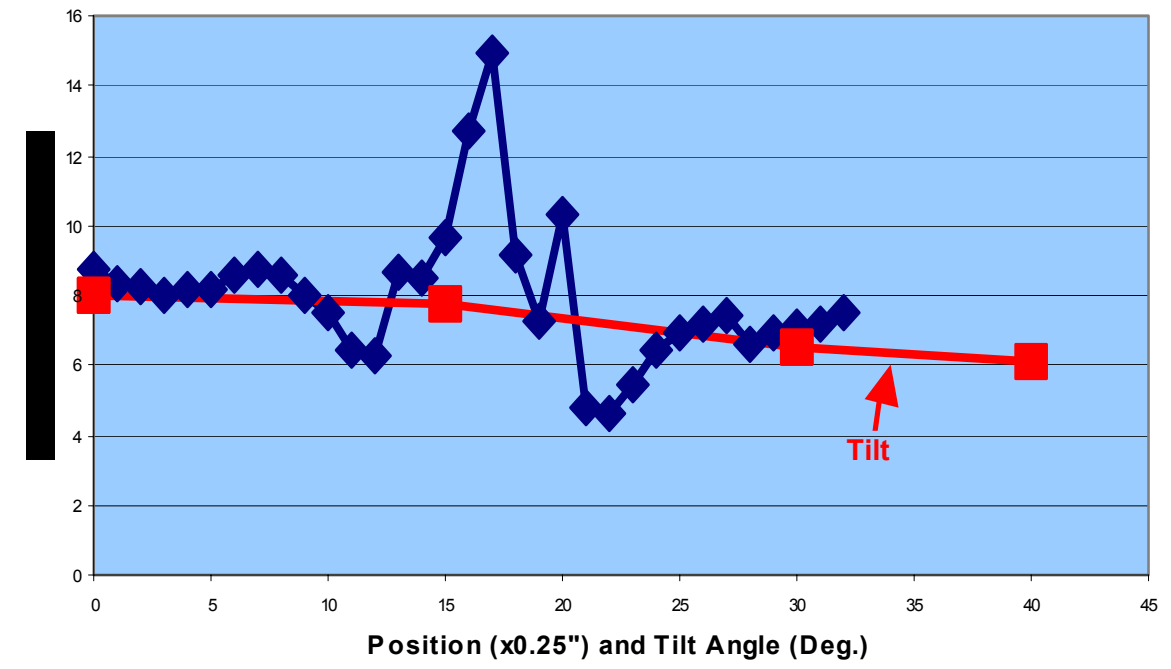

Figure 11. Tilt and defect response from standard probe with rounded pole tips

The Tuboscope solution to the tilt and liftoff problems was a double-linked suspension system that was designed to maintain constant contact between the probe and the pipe surface during transition across a dent surface. This arrangement is shown later in the report. 


\section{RESULTS AND DISCUSSION}

\subsection{General NLH Measurement}

The state of stress in steel changes its magnetic hysteresis curve. The NLH technique seeks to quantify stress by a measurement of third harmonic distortion created by the hysteresis in a transformer-like sensor. The idea behind the NLH measurement is diagrammed in Figure 12 for a single sensor. This sensor is just a transformer whose core consists of a linear ferrite core magnetic path, completed by the pipe steel to be measured. The primary (transmitter) coil is driven by a $10-\mathrm{kHz}$ very pure sine wave. A small $30-\mathrm{kHz}$ third harmonic is generated by the steel and is picked up in the secondary (receiver) coil, along with $10-\mathrm{kHz}$ signal from the transmitter.

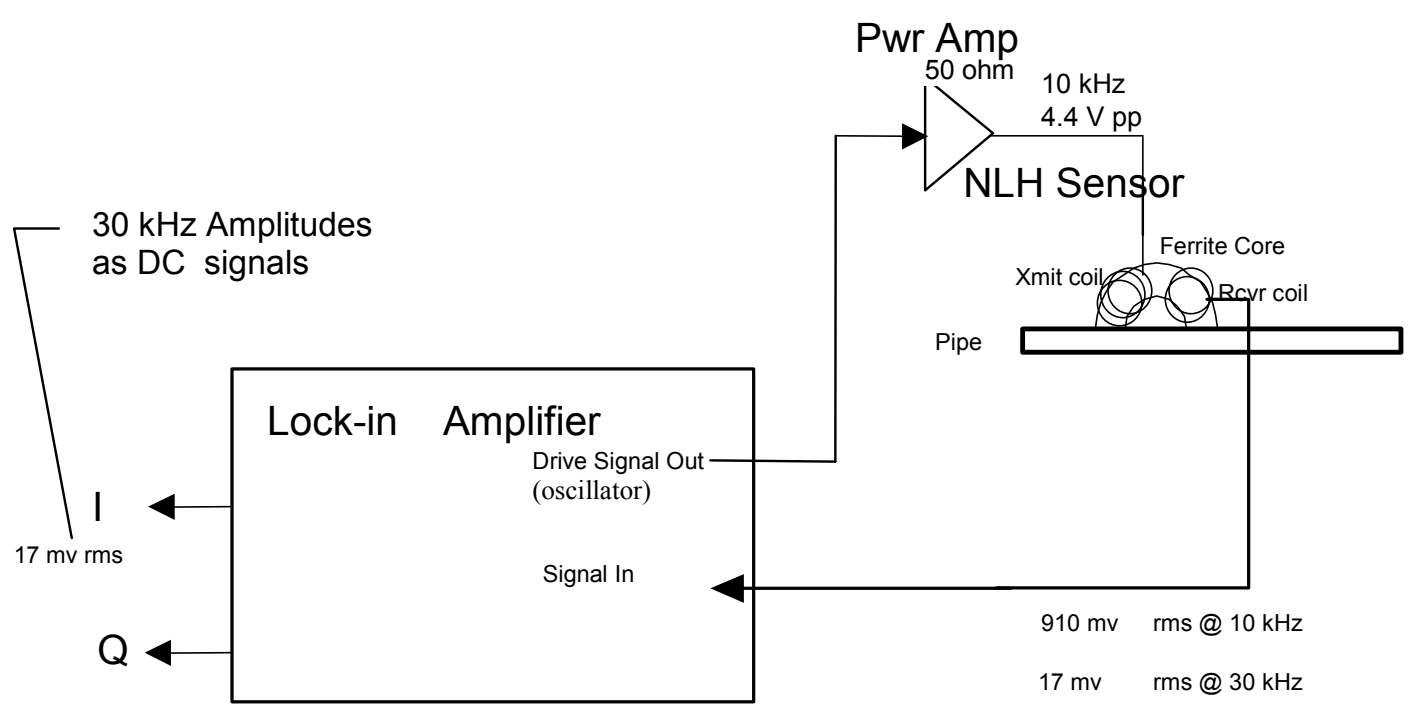

Figure 12. SwRI NLH system using laboratory equipment

For a constant $10-\mathrm{kHz}$ amplitude, the $30-\mathrm{kHz}$ amplitude depends on the stress and is picked up by the secondary (receiver) coil on the same core as the transmitter. The amplitude and phase of the $30-\mathrm{kHz}$ signal is then measured and spatially sampled. This is a complex electronic process that involves filtering out the $10-\mathrm{kHz}$ signal, which is much larger than the $30 \mathrm{kHz}$, amplification of the $30 \mathrm{kHz}$, detection, time sampling, analog-to-digital conversion, and storage.

The one sensor could be scanned along the pipe and yield stress data for the scanned stripe. For a two-dimensional image of the stress, a circumferential (or transverse) array of multiple sensors would be scanned. In a practical pipe inspection system, the array would have a circumferential sensor spacing of 0.5 to 2 inches $(12$ to $50 \mathrm{~mm})$. The longitudinal sampling, normally set by the recorder electronics, might vary from a minimum of $0.1 \mathrm{inch}(2.5 \mathrm{~mm})$. The exact sampling requirements for in-line inspection are not known at this time. One outcome hoped for from this work was some experience and requirements for longitudinal sampling and sensor spacing. Note that the minimum spatial resolution (circumferential by longitudinal) of the sensor and hence the spatial sampling are approximately determined by the separation and width of the poles in the sensor core. 
There are many approaches to the $30-\mathrm{kHz}$ measurement. In initial feasibility work, SwRI used large laboratory units - a linear power amplifier to drive the transmitter coil and a lock-in amplifier to measure the $30 \mathrm{kHz}$ coherently. Note that a lock-in amplifier works essentially as a super-heterodyne receiver combined with a digital voltmeter for very narrow band signals. It can measure the following for $10 \mathrm{kHz}$ or any of its harmonics: in-phase amplitude, quadrature amplitude, magnitude, and phase. These are available as slowly varying numerical values within the $50-\mathrm{Hz}$ detection bandwidth.

Some typical signal characteristics are given in Table 1 . The sensor impedance is about 30 ohms at $10 \mathrm{kHz}$ ). The power to drive each sensor is manageable even if there are many sensors.

Table 1: Typical SwRI Lab Signal Characteristics

\begin{tabular}{lll}
\hline Parameter & Value & Remark \\
\hline Drive Voltage & & All measurements on a steel sample \\
Amplitude $10 \mathrm{kHz}$ & $4.4 \mathrm{~V} \mathrm{ptp}$ & \\
Power/ Sensor & $18 \mathrm{~mW}$ & \\
Duty Cycle & Continuous & \\
Harmonic Distortion @ $20 \mathrm{kHz}$ & $-55 \mathrm{db}$ (or 0.2\%) & Below 4.4 V ptp \\
$\quad$ Harmonic Distortion @ $30 \mathrm{kHz}$ & $-40 \mathrm{db}$ (or 1\%) & Below 4.4 V ptp \\
Sensor Impedance (magnitude) @ 10 kHz & 44 ohms & Nominal, on steel \\
Input & & All measurements on sample \\
Nominal Level & & \\
$10 \mathrm{kHz}$ & $900 \mathrm{mV}$ rms & \\
$20 \mathrm{kHz}$ & $<4 \mathrm{mV} \mathrm{rms}$ & \\
$30 \mathrm{kHz}$ & $17 \mathrm{mV} \mathrm{rms}$ & \\
Sensor Impedance (magnitude) @ 10 kHz & $38 \mathrm{ohms}$ & Nominal, on steel \\
Estimated Noise \& DC Bias & & \\
$10 \mathrm{kHz}$ & $15 \mathrm{mV} \mathrm{rms}$ & \\
$20 \mathrm{kHz}$ & $0.05 \mathrm{mV}$ rms & \\
$30 \mathrm{kHz}$ & $0.1 \mathrm{mV}$ rms & \\
Output Bandwidth & $50 \mathrm{~Hz}$ & \\
\hline
\end{tabular}

\subsection{Commercial Prototype Design}

\subsubsection{Sensor}

The Tuboscope prototype sensor core design was like the latest probe from SwRI but with sloped, not rounded, poles. The sloped core was shaped to maximize pole contact with the surface to be measured. The core dimensions, material, and windings were the same as those of the SwRI sensor. As shown in Figures 13 and 14, the prototype wound core was encapsulated into an aluminum-trailing arm so that the poles were flush with the arm surface. Four ruby beads provided hard points for the sensor to run on and lift the pole faces (and the rest of the sensor surface) at least 0.01 inch $(0.25 \mathrm{~mm})$ for protection from the pipe surface. The trailing arm mount was chosen because it would allow flexing over bumps but maintain good contact at the NLH poles. (This device is patented by Tuboscope.) This mount also allowed the NHL sensors 

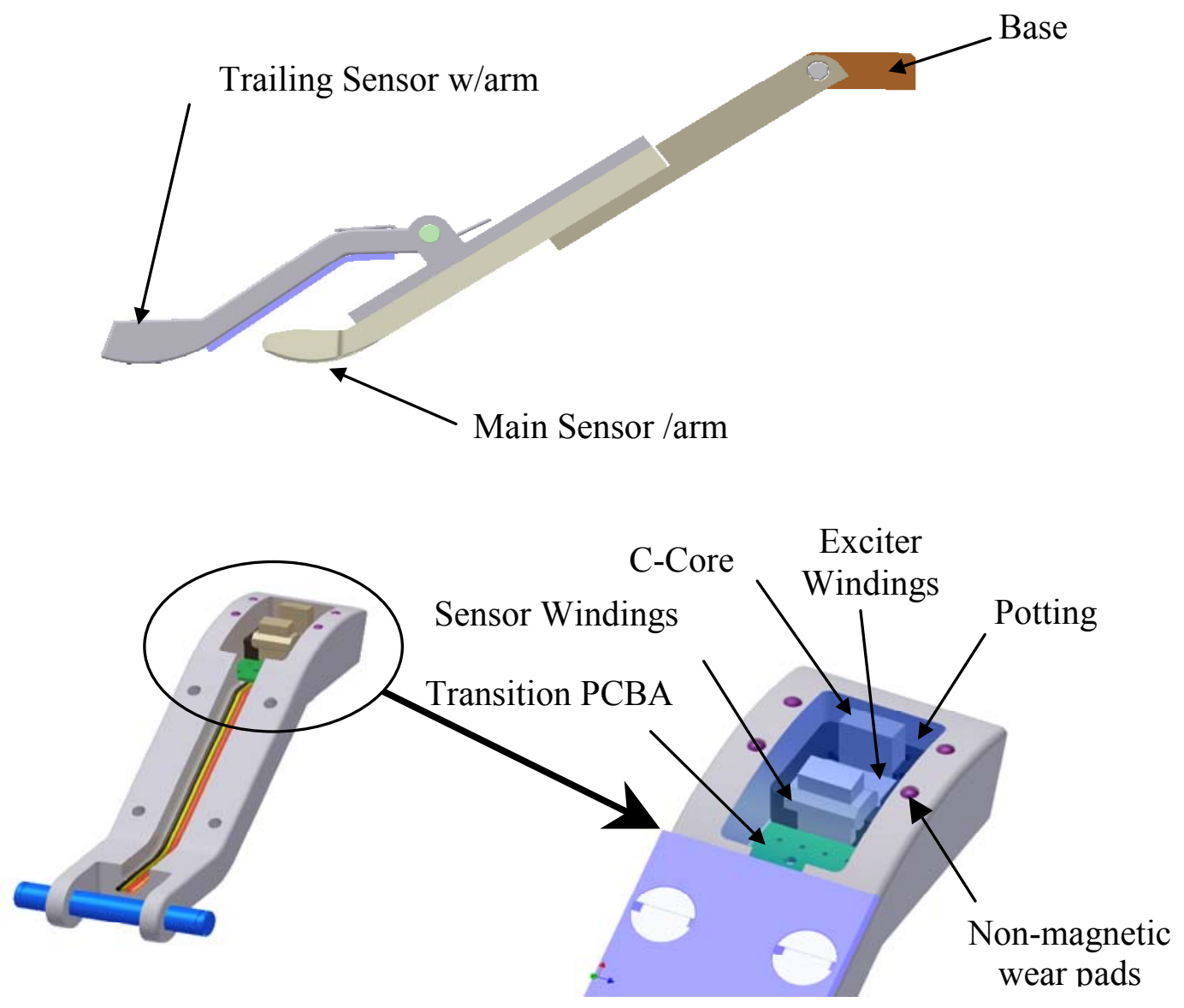

Figure 13. Sensor diagram

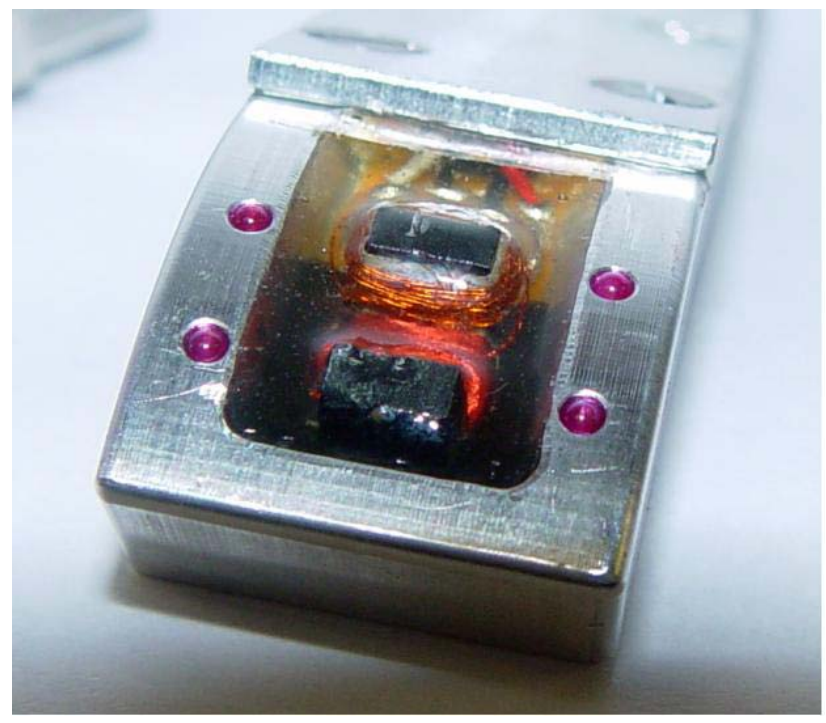

Figure 14. Close-up of the encapsulated sensor core and coils 
to be simply deployed on a tool (without extra mount rings or an increase of a tool's minimum bend radius) in combination with other sensors, such as ID discrimination coils or reduced field Hall sensors in the main arm. The trailing arm was spring-loaded to the main arm, which also provided extra protection for the NLH core from pipe weld drop-through and debris. Additional views are shown in Figures 15 and 23.

Allowing for cable capacitance, the nominal impedances of the SwRI and Tuboscope prototype sensors were the same. However, the Tuboscope receiver coil was connected by a much more rugged 26-gage twisted/shielded cable. This was because the ultrafine gage coax on the SwRI sensor was deemed much too light to survive in a pipeline.

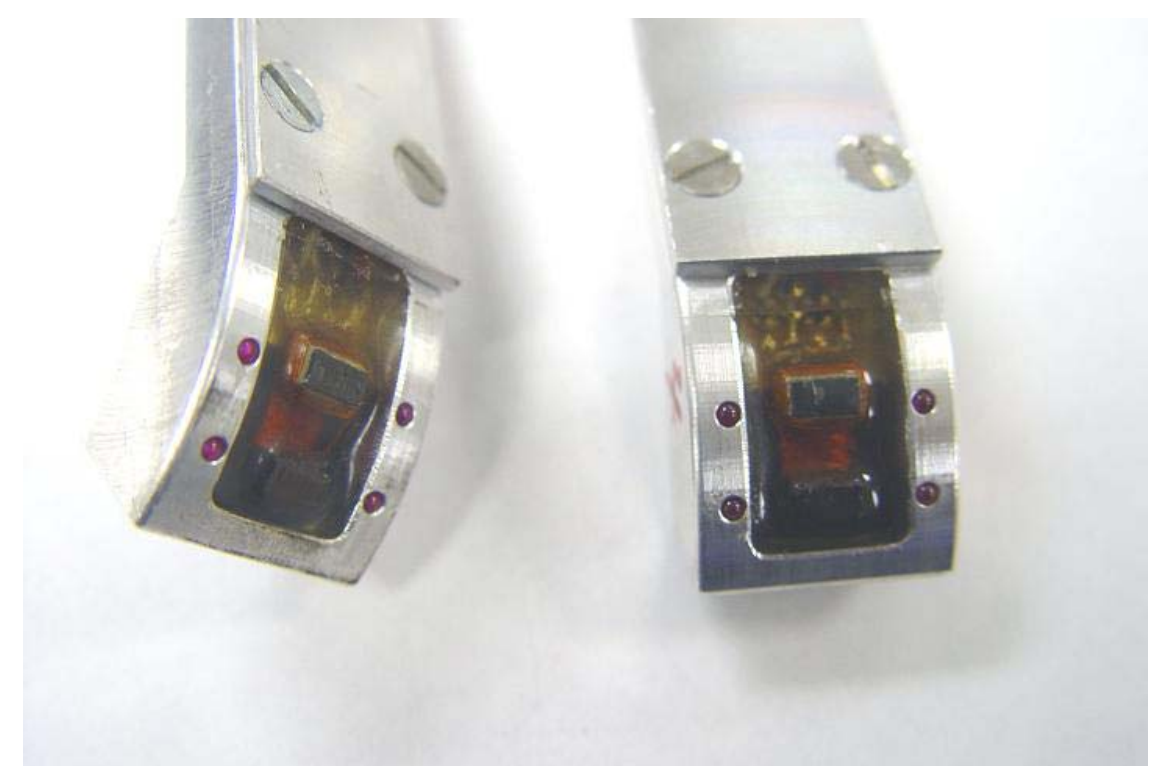

Figure 15. Actual NLH sensors

\subsubsection{Sensor Front End (Drive and Detection)}

Because a project goal was use of the NHL concept in a commercial in-line inspection system, electronics would have to be more compact and energy efficient and must easily allow for multiple sensors. To meet this end, the architecture, shown in Figure 16 for one sensor, was adopted. Figure 17 shows how the front end fits in the overall commercial system, Tuboscope's Linalog ${ }^{\circledR}$ MAX recorder. In it, the NLH front end is embedded in one of the multiplexer/ ADC (MUX) units. These accept analog voltages from the NLH and other sensors, and convert to digital streams (12 bit) that are communicated to the main recorder. The recorder groups, compresses, and stores the sensor data in a large memory store along with distance and other utility data. The recorder controls the whole acquisition process via its odometer wheel interface and demands acquisition and data from its attached MUX units. With its software, the $\operatorname{Linalog}^{\circledR}$ MAX recorder can record and then display over 1000 parallel channels. 


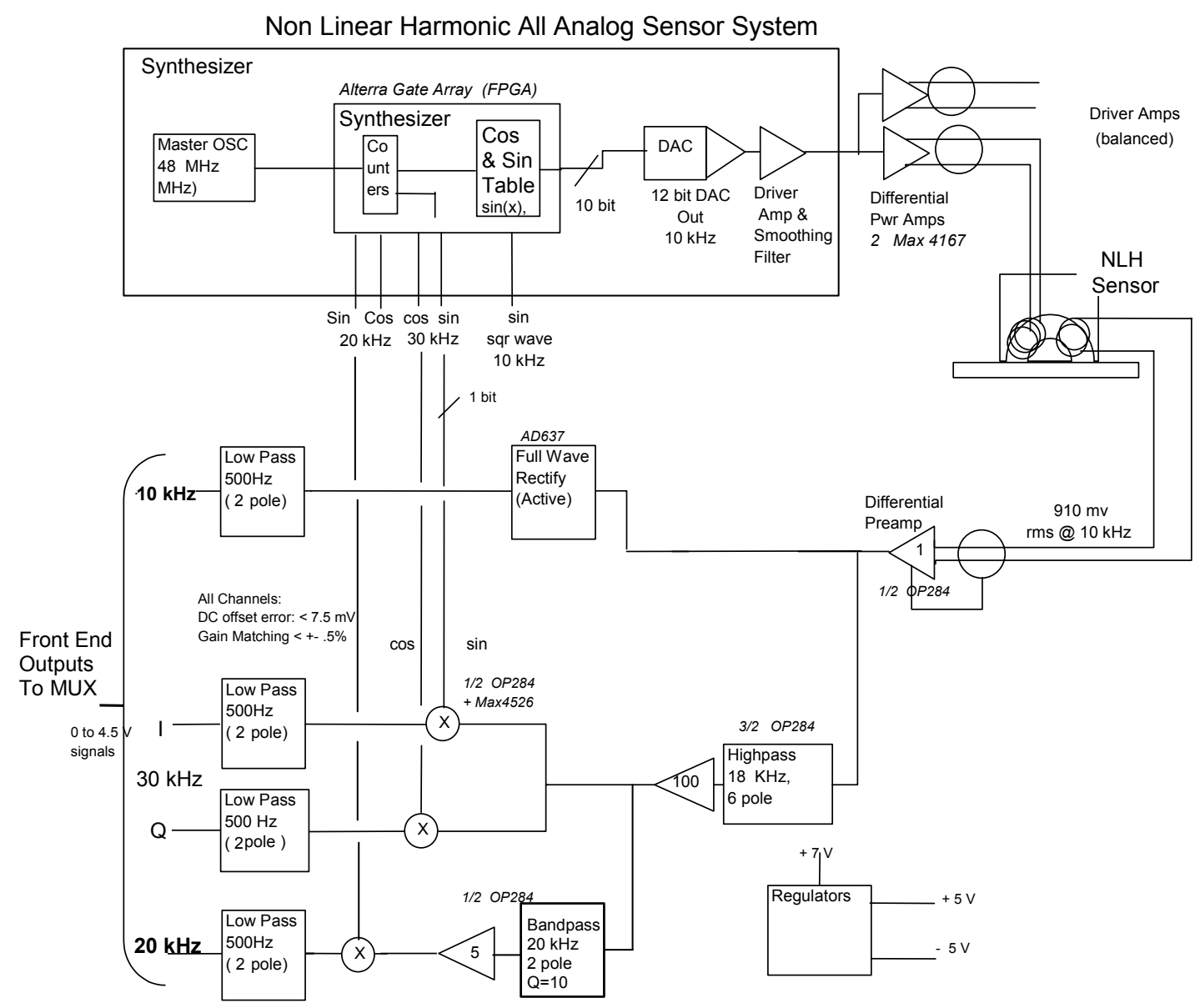

Figure 16. NLH prototype front end single channel

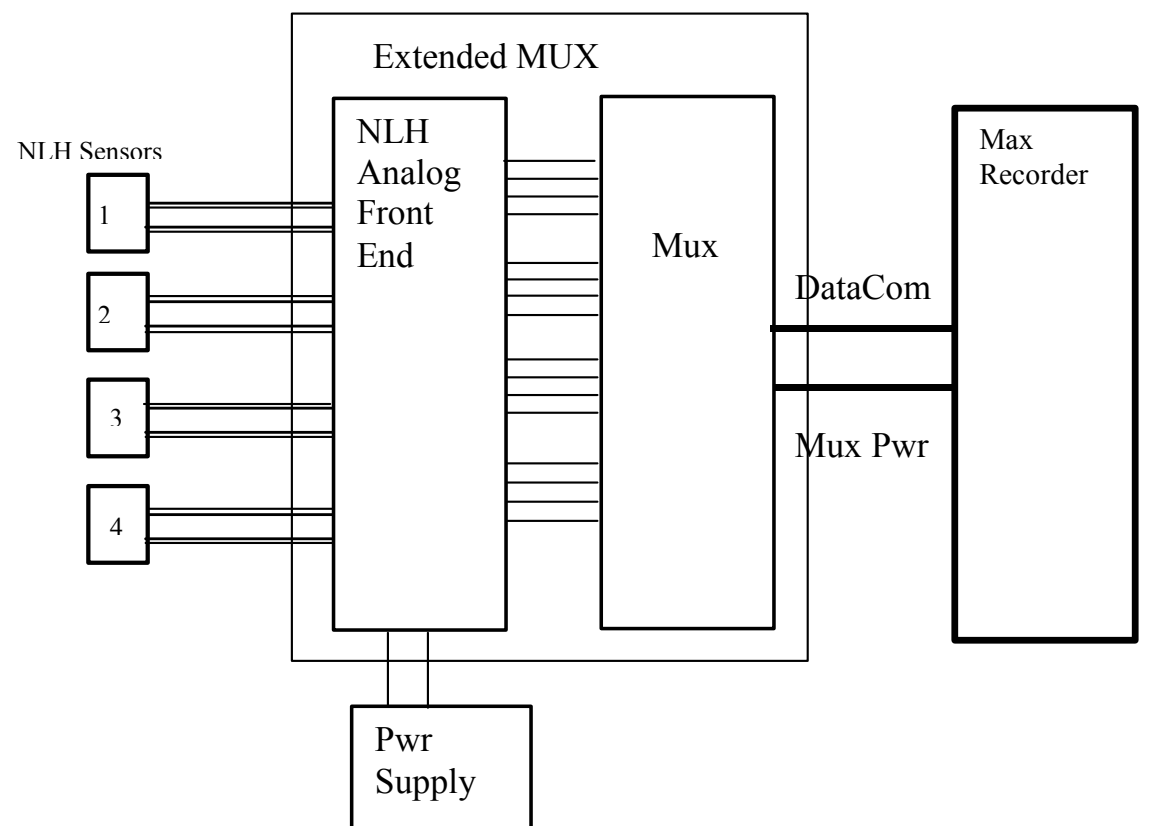

Figure 17. Overview of the NLH electronics 
This front end essentially duplicates the detection function of the SwRI lock-in amplifier but is amenable to compact and low-power electronics. In addition to the $30-\mathrm{kHz}$ inphase and quadrature amplitude (labeled $30 \mathrm{kHz}$ I and $30 \mathrm{kHz}$ Q) similar to those of the SwRI lock-in amplifier, it provides $10-\mathrm{kHz}$ magnitude and $20-\mathrm{kHz}$ in-phase outputs (labeled $10 \mathrm{kHz}$ and $20 \mathrm{kHz}$ ). All of these are available in parallel, sampled, and stored together simultaneously by the recorder.

The $10-\mathrm{kHz}$ and $20-\mathrm{kHz}$ measurements were added to check on practical aspects of the technique in a pipeline environment. The $10-\mathrm{kHz}$ amplitude is sensitive to sensor liftoff and could be used to determine liftoff conditions and help compensate for them. The $20 \mathrm{kHz}$ should be sensitive to remanent magnetism in the steel that could affect the $30-\mathrm{kHz}$ measurement. The $20 \mathrm{kHz}$ is an independent channel that could be used to detect and compensate for remanent magnetism effects. In effect, there is little phase shift, so the $20 \mathrm{kHz}$ is essentially a magnitude measurement.

In the front end, each sensor transmitter coil has its own power amplifier. Each power amplifier has a fully differential output (balanced, push-pull) so as to minimize distortion in its output and achieve a 4.4 volt peak-to-peak output with only a 5 -volt supply. Note that in Figure 16, the references in italics over each block are a chip count and type for implementation.

The unit labeled "synthesizer" is common to all sensors. It creates a very pure 10$\mathrm{kHz}$ cosine wave from data samples of the cosine in a field-programmable gate array (FPGA) that drives a DAC at an output sample period of about $1 \mu \mathrm{s}$. The FPGA also outputs 10-, 20-, and $30-\mathrm{kHz}$ (at 0 and 90 degrees) square wave reference signals that are synchronized to the $10-\mathrm{kHz}$ cosine data, as diagrammed in Figure 16 and output in Figure 18. Although it seems complicated, the synthesizer box is comprised of an oscillator and part of the FPGA that are already in the MUX unit. Thus, it only adds an 8-pin DAC and OP amp, which are spread over all the sensors.

The crux of the detection part of the front end is that the receiver coil signal contains the 10-, 20-, and $30-\mathrm{kHz}$ signals combined, but that the $10-\mathrm{kHz}$ amplitude is more than 50 times larger than the 10 and $20 \mathrm{kHz}$, which are so small they must be amplified before any detection or conversion at the MUX. This is further complicated because the $10 \mathrm{kHz}$ is large and directly detectable at the coil. Although this makes detection of $10-\mathrm{kHz}$ amplitude easy, detection of $20 \mathrm{kHz}$ and $30 \mathrm{kHz}$ is problematic. This is because if the coil signal were amplified too much, it might saturate, distorting or masking the true $20-$ and $30-\mathrm{kHz}$ signals. Additionally, 20 and $30 \mathrm{kHz}$ are difficult to separate from $10 \mathrm{kHz}$ by filtering because filters work on a per-octave basis, and 20 and $30 \mathrm{kHz}$ are only 1 and 1.5 octaves away from $10 \mathrm{kHz}$. This is relatively close and requires many filter poles or stages to attenuate one relative to the other.

The receive part of the front end for each sensor begins with a low-distortion, lownoise differential amplifier that rejects noise pickup in the receive cable and buffers the input signal to drive four separate detector subsections. For $10 \mathrm{kHz}$, this buffer amplifier goes directly to an amplitude detector, which is a precision full-wave rectifier followed by a low-pass filter. This is all contained in one chip. Note that to reduce the chip count in the electronics, 20- and $30-\mathrm{kHz}$ components are not removed by prefiltering because they are small (1/50 or less) of the $10 \mathrm{kHz}$ and may only make an error of 2 percent in the $10-\mathrm{kHz}$ amplitude. 
To circumvent the dominance of the $10 \mathrm{kHz}$, a high-pass filter partially separates $30 \mathrm{kHz}$ and $20 \mathrm{kHz}$ by forming an intermediate signal. This signal contains $10 \mathrm{kHz}$ at a low enough level so it can be amplified by 100 to bring the $30-\mathrm{kHz}$ amplitude up a practical level. The $30 \mathrm{kHz}$ I and Q (in-phase and quadrature) are then each synchronously detected by a special multiplier, multiplied by a +1 or -1 according to its $30-\mathrm{kHz}$ demodulation controls. Each desired output appears at low frequency (DC to $<500 \mathrm{~Hz}$ ), and the low-pass filter eliminates the unwanted fundamental and intermodulation components (at 10, 20, and $30 \mathrm{kHz}$ ). The $30-\mathrm{kHz}$ magnitude and phase can be obtained by post-processing in the playback software.

The low-pass detection filter, 0 to $500 \mathrm{~Hz}$ in bandwidth, sets the maximum logging speed. Below the maximum tool speed, the signal bandwidth is less than $500 \mathrm{~Hz}$, and NLH signals will then pass undistorted. Assuming the sensor acts spatially as a rectangular averager, its signal (temporal) bandwidth is approximately the ratio of speed (inches per second) to averaging length (inches), the pole-to-pole core distance. For the targeted sensors, pole-to-pole of 0.4 inch $(10 \mathrm{~mm}), 500 \mathrm{~Hz}$ corresponds a maximum speed of about 12 miles per hour $(5.4 \mathrm{~m} / \mathrm{s})$.

How the synchronous detection process works for the $30 \mathrm{kHz}$ in-phase component is illustrated in a paragraph and figures that follow. Examples of signals and their detection are shown in Figures 18 through 20. Note that (1) in reality, the $10 \mathrm{kHz}$ would be much larger than the 20 or $30 \mathrm{kHz},(2)$ the demodulation controls are + and - 1, and (3) 30- and 20-kHz amplitude would be unequal.

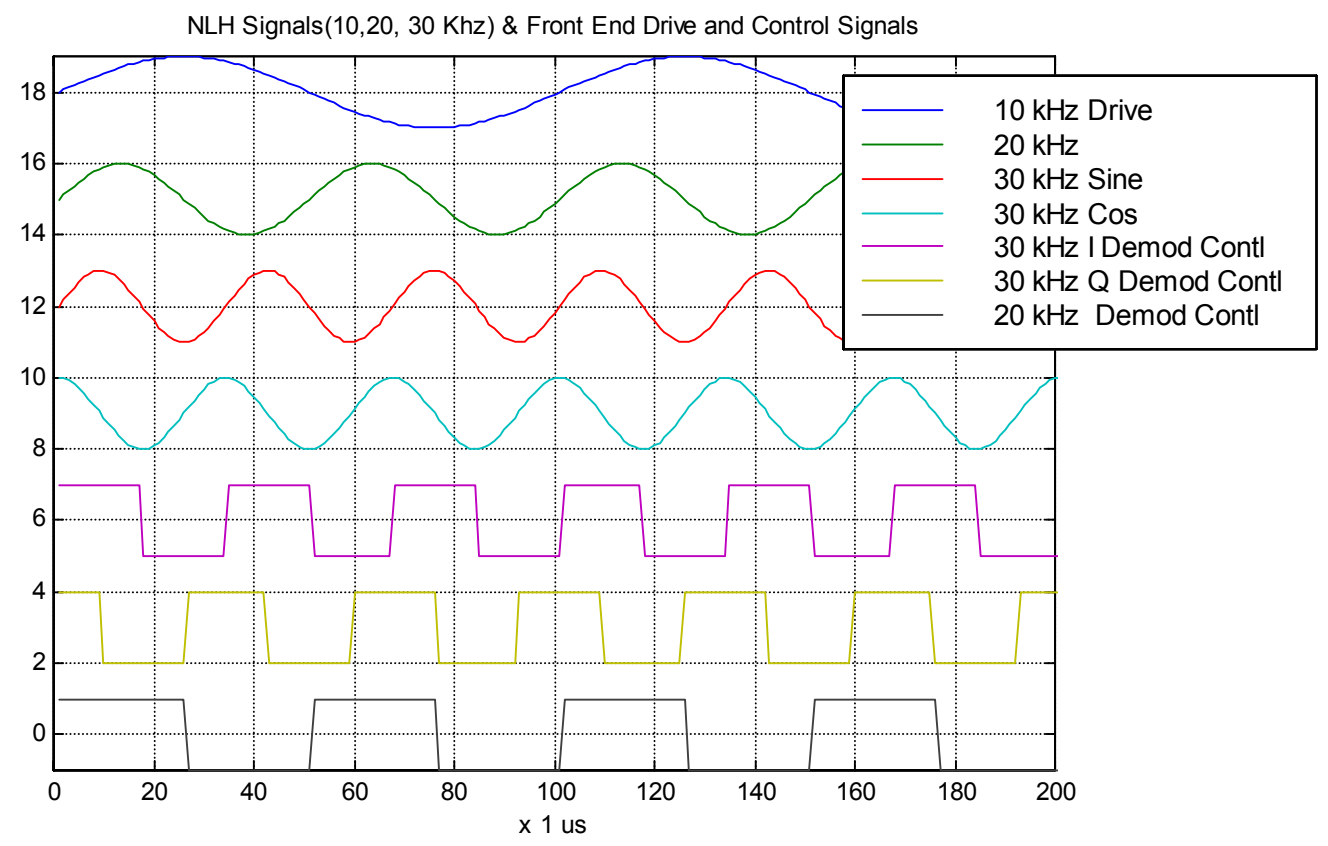

Figure 18. NLH signals and front end controls 


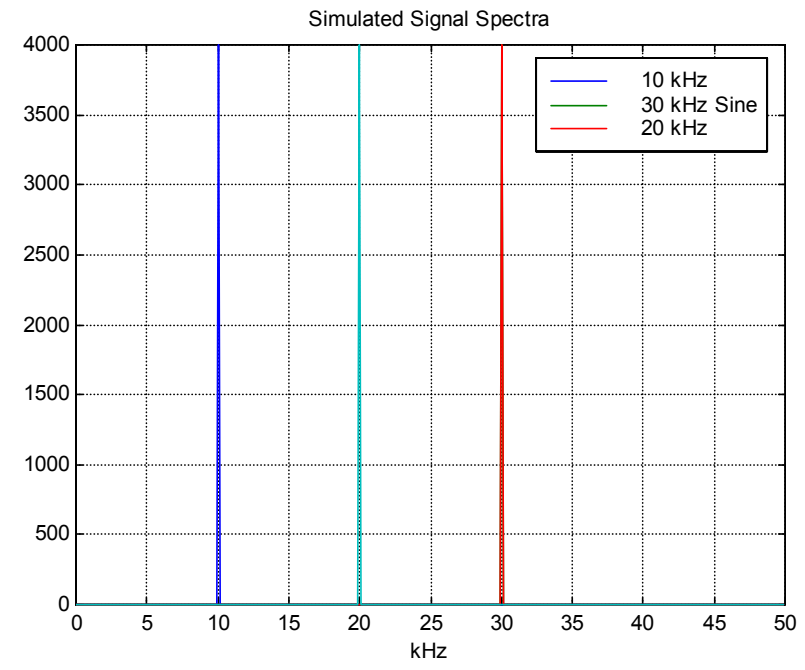

Figure 19. A simulated signal spectrum input
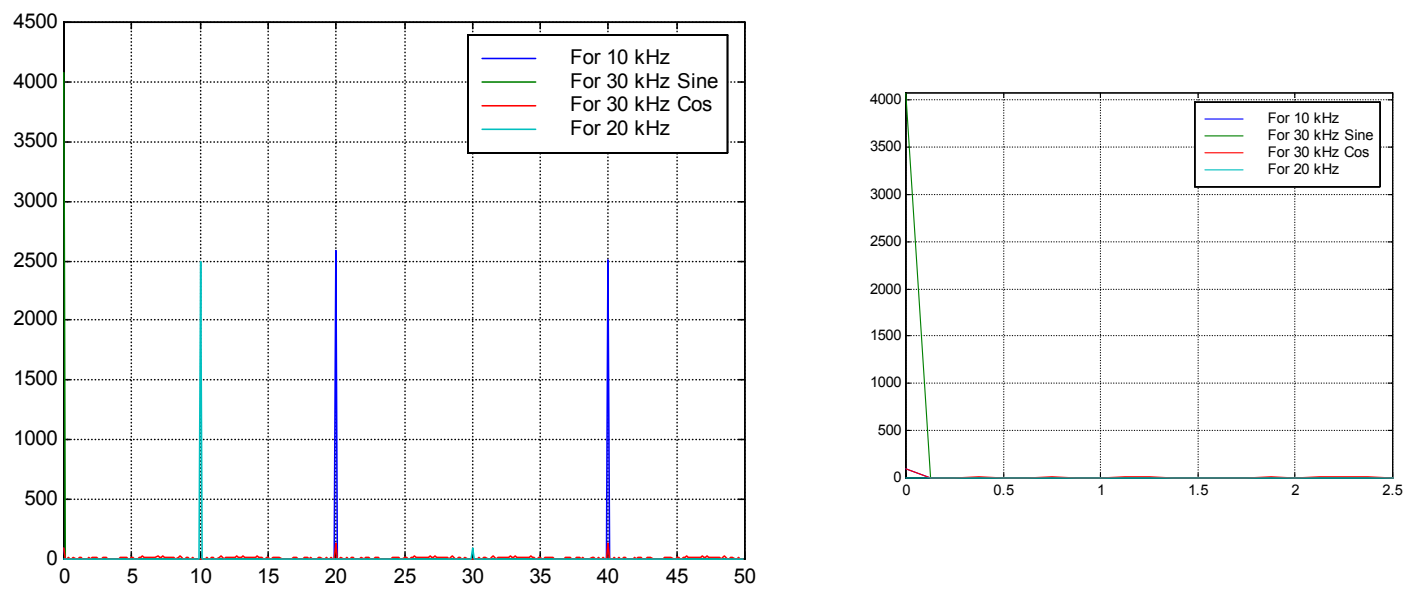

Figure 20. $30 \mathrm{kHz}$ I detector output spectrum (before low-pass filtering)

The reason for using synchronous detectors is clear when considering the $30-\mathrm{kHz}$ in-phase detector. As shown in Figure 19, its demodulation shifts the $30 \mathrm{kHz}$ down to DC, the 10 $\mathrm{kHz}$ up to $20 \mathrm{kHz}$, and thus separates the two by more than five octaves. This makes the filter to remove $10 \mathrm{kHz}$ simple, and a two-pole passive filter provides more than $60 \mathrm{~dB}$ of rejection of 10 $\mathrm{kHz}$. This is in contrast to filtering directly at $30 \mathrm{kHz}$, which would have required eight poles (four active stages) and would be sensitive to mistuning. Figure 19 also shows that at the 30 $\mathrm{kHz}$ I detector, the spectral level for a $30-\mathrm{kHz}$ cosine (a possible quadrature signal) is near zero, so that any cosine (quadrature) component cannot falsely appear as an in-phase. This is because the sine and cosine are "orthogonal."

Figure 21 shows what happens in the time domain for the $30 \mathrm{kHz}$ I synchronous detector (multiplier output only) for various pure inputs. For the $30 \mathrm{kHz}$, the mean value is positive. For all the others, including the $30-\mathrm{kHz} \sin$, the mean value is zero. The mean values are extracted by the averaging done by the low-pass filters. 


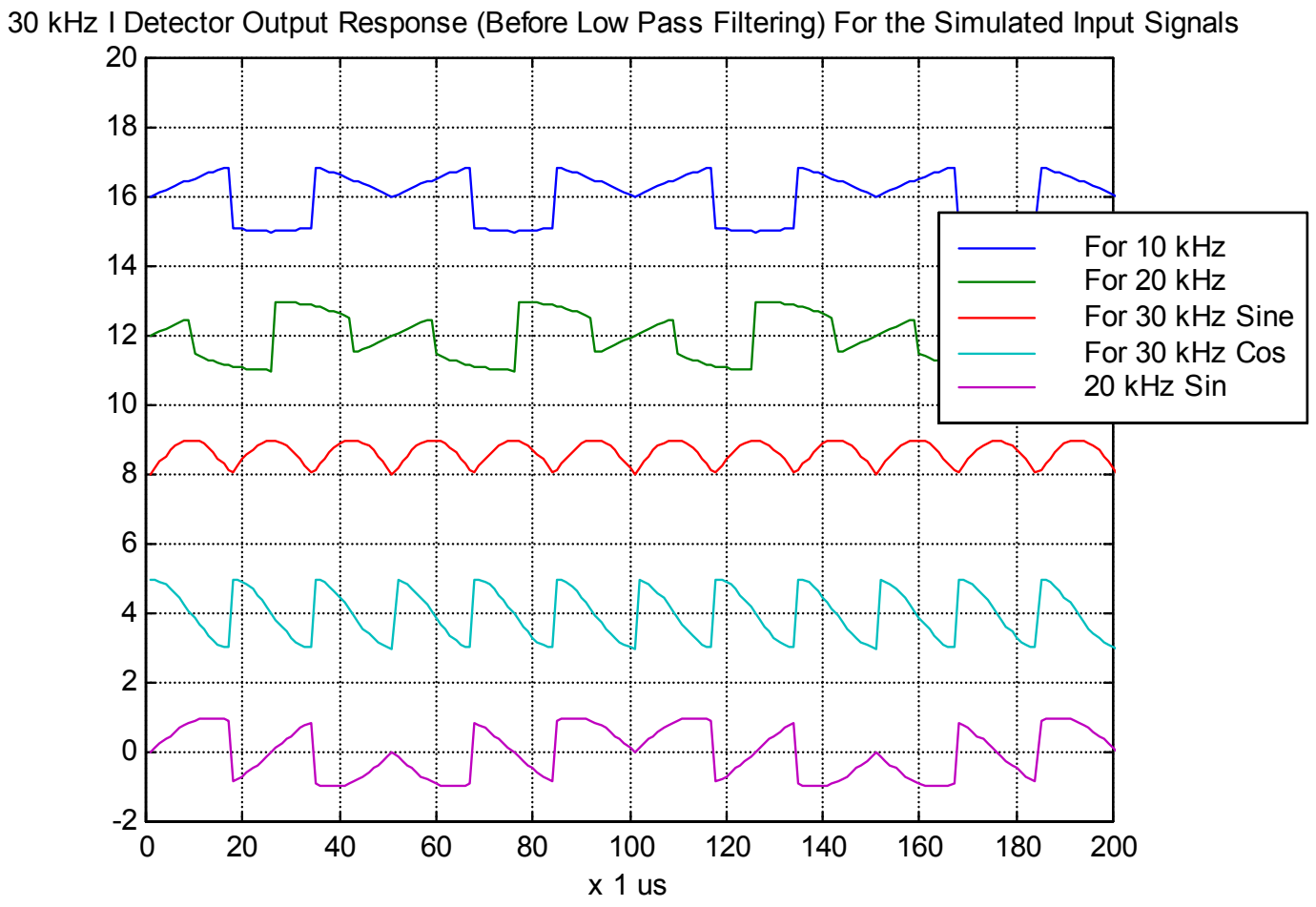

Figure 21. NLH detection signals

The synchronous detector lends itself to modern chips and integration by means of a few CMOS switches, a moderate performance op-amp, and an RC filter. Although it is very simple, DC offsets caused by switching, op-amp offset, and op-amp slew limiting can cause errors. For the prototype, these were avoided by means of a balanced switch (for which the switching transients nearly cancel) and a low-offset, yet low-power, op-amp. DC error was less than $1 \mathrm{mV}$ for output signals of $160 \mathrm{mV}$ (with the sensor on the plate).

The $20-\mathrm{kHz}$ detection is similar to that of the $30 \mathrm{kHz}$. The difference is that because so little $20 \mathrm{kHz}$ was seen after the high-pass filter, the input to the $20-\mathrm{kHz}$ detector was bandpass filtered (around $20 \mathrm{kHz}$ ) and then amplified by 5 . This was to make the $20-\mathrm{kHz}$ detection easier by suppressing 10 and $30 \mathrm{kHz}$ and boosting the $20 \mathrm{kHz}$.

The previous front end is good as a first commercial prototype. It lends itself a low chip count, low power, and low area per sensor; it allows simple realtime scope monitoring intermediate signals and final outputs (for debugging); it is simple to construct; and it adapts easily to Tuboscope's commercial recorder. In fact, a printed circuit board of NLH detection circuits could substitute for those dedicated to reduced field sensors in a commercial system. 


\subsection{Test Setup and Test Procedure}

In order to demonstrate commercialization, a plate of pipeline steel having stress-raising damage was scanned by an array of four NLH sensors, spaced 1.5 inches center to center. The data were recorded by the Linalog ${ }^{\circledR}$ MAX recorder. A block diagram of the system connections is shown in Figure 22. Photographs of the test setup and sensor array are shown in Figures 23 and 24. The sensor array was fixed to an arm, which was driven by a motor via a rack and pinion in order to scan the array along the length of the plate at $0.72 \mathrm{mph}(0.32 \mathrm{~m} / \mathrm{s})$. An encoder wheel moving on the rack sent pulses to the recorder, just like the odometer wheel in a commercial tool. However, the record interval was 0.0048 inch $(0.12 \mathrm{~mm})$ instead of 0.1 inch $(2.5 \mathrm{~mm})$. As in a tool, each drive pulse would cause acquisition and storage of a sample of each input.

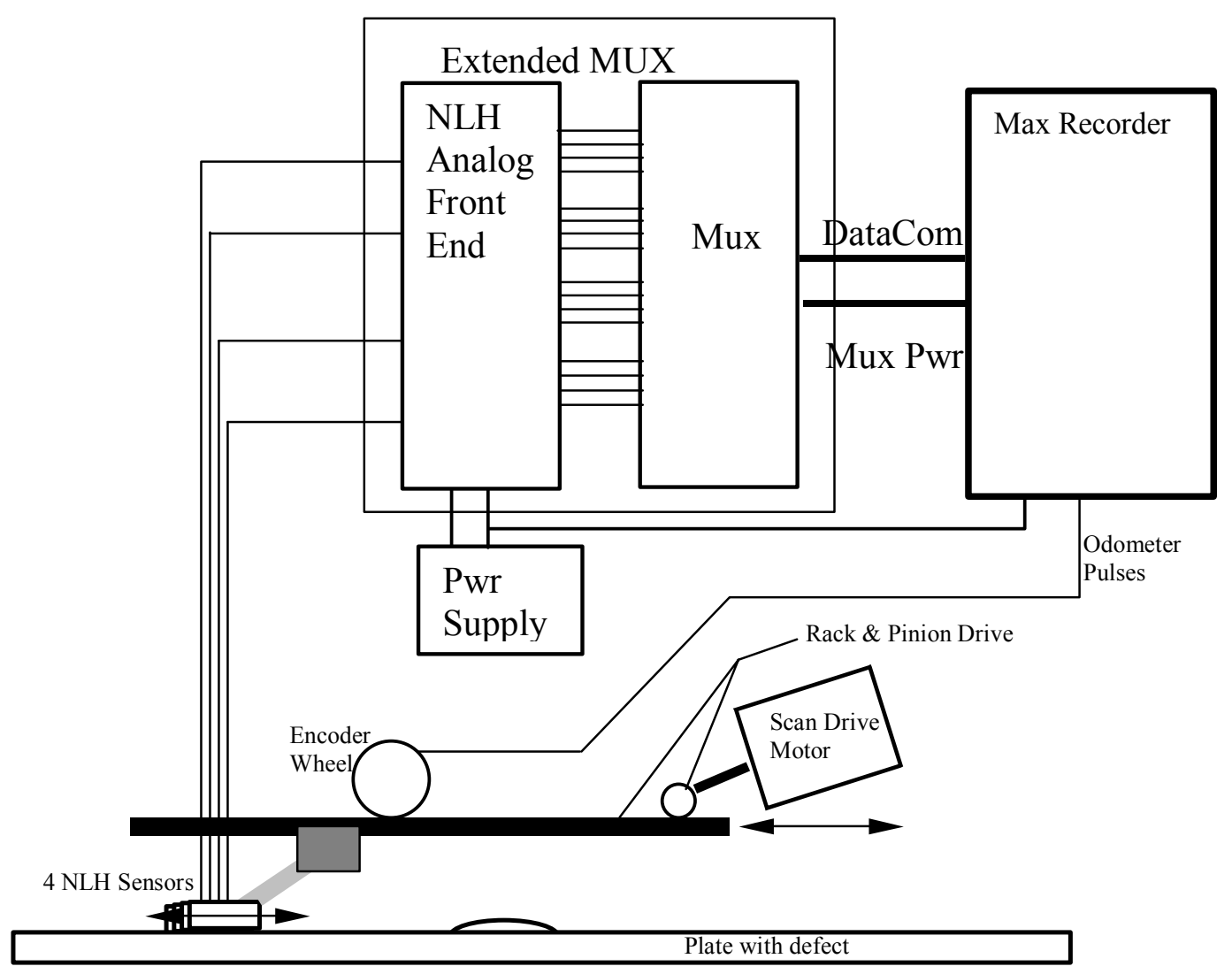

Figure 22. Prototype four-sensor NLH system setup for test scanning 


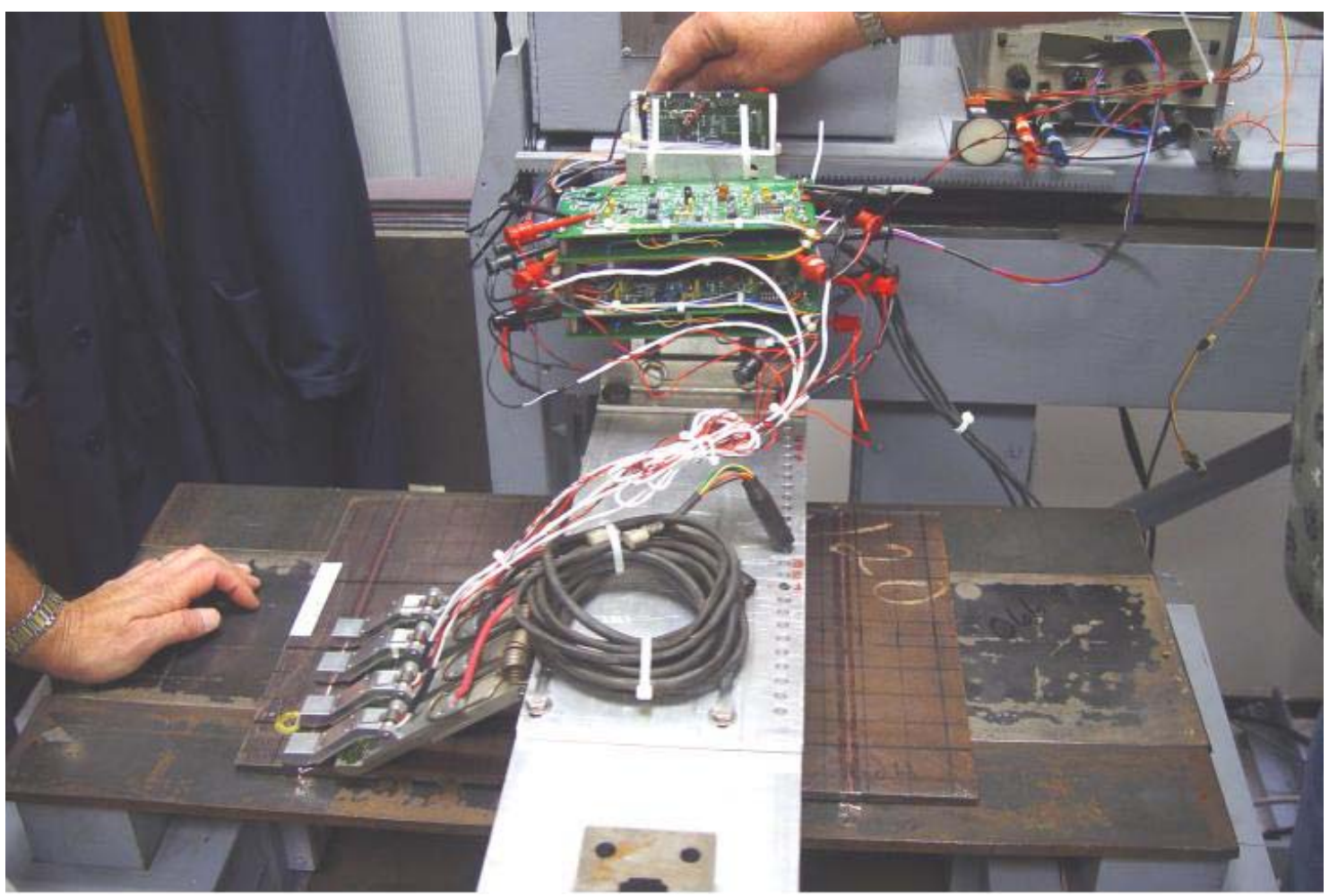

Figure 23. NLH commercial prototype test system setup

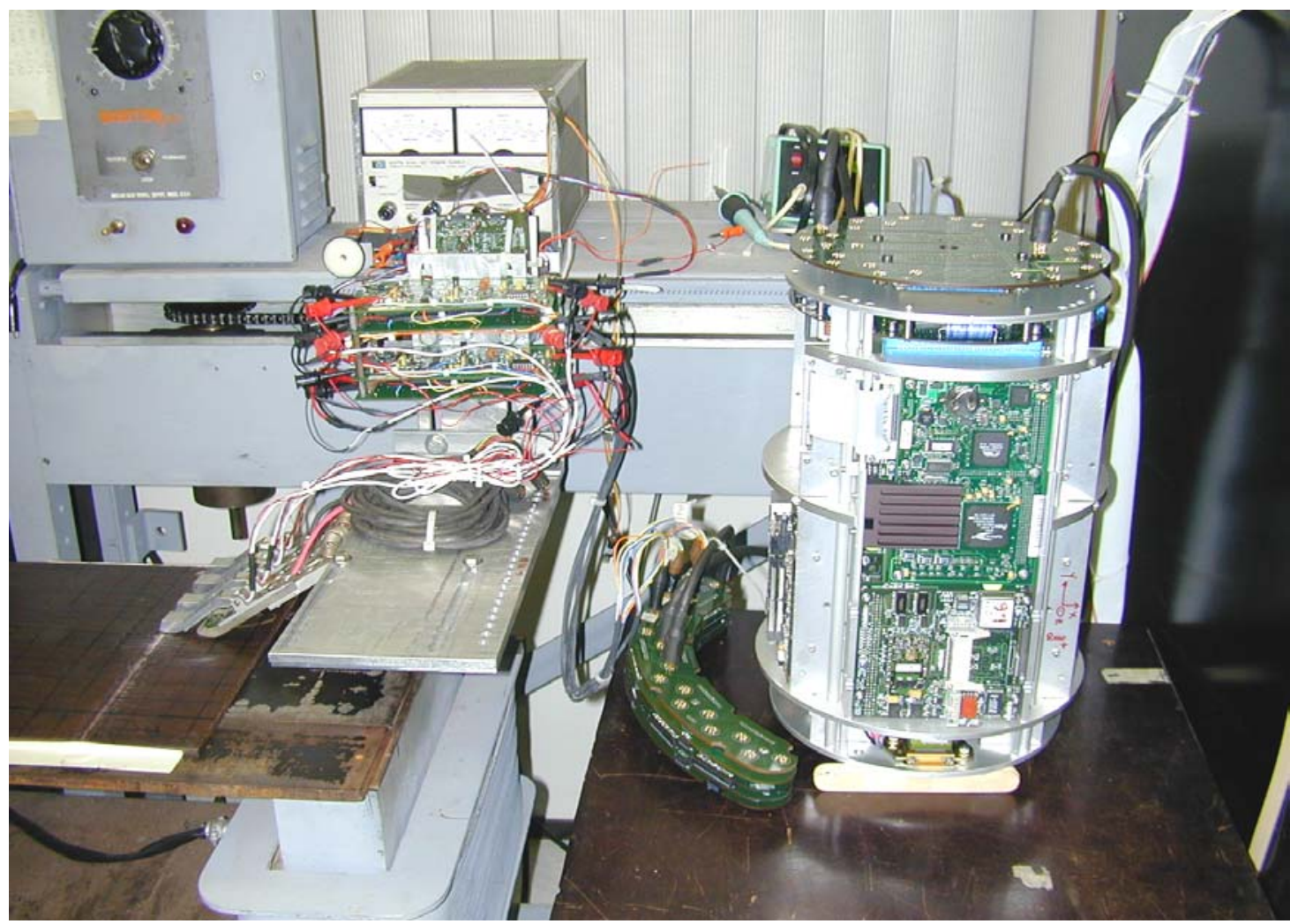

Figure 24. NLH test setup with Linalog ${ }^{\circledR}$ MAX recorder and MUX unit 
Figure 22 shows the sensors connected to the four detection circuits that then fed 16 channel inputs of a multiplex/ADC unit (Mux) of the Linalog ${ }^{\circledR}$ MAX recorder. When logging, the Mux unit takes a 12-bit sample of each input and then transmits these data to the Linalog ${ }^{\circledR}$ MAX recorder unit as if it were running in a pipeline. The main recorder has the odometer interface and controls transmission and stores data from the Mux plus distance in its mass memory store. Later, the Linalog ${ }^{\circledR}$ MAX recorder uploads these data to a PC for further manipulation and display.

The plate was $17-3 / 4$ inches $(450 \mathrm{~mm})$ (X direction) by 12 inches $(300 \mathrm{~mm})$ (Y or transverse direction) and had a defect near its center. From the top of the plate, visibly, the defect appeared as a slight bulge [ 4.5 inches by 1 inch $(\sim 114 \mathrm{~mm}$ by $2.5 \mathrm{~mm})]$. From the rear, the defect appeared as a gouge. The plate was scanned over an area 13-1/2 inches (343 $\mathrm{mm})(\mathrm{X})$ by 12 inches $(305 \mathrm{~mm})(\mathrm{Y})$, which was demarked by wires. The sensor orientation (i.e. the pole-topole direction) was aligned with the long axis of the plate. This is the same way as comparative SwRI data were taken.

The sensor array consisted of four sensors locked together on an arm and spaced 1.5 inches $(38 \mathrm{~mm})$ apart (center-to-center), so they spanned 4.5 inches $(114 \mathrm{~mm})$. To cover the scan area with the array and have an effective transverse spacing of 0.5 inch $(12 \mathrm{~mm})$, multiple scans were done. Three scans were done, advancing 0.5 inch $(12 \mathrm{~mm})$ in Y after each. This covered the first 6 inches $(150 \mathrm{~mm})$ in the $\mathrm{Y}$ direction. The whole array was then shifted in Y by 6.5 inches $(165$ $\mathrm{mm})$, and another three scans were made, advancing 0.5 inch $(12 \mathrm{~mm})$ after each. This then covered from 6.5 to 12 inches (165 to $305 \mathrm{~mm}$ ).

To create data that appeared to be created from a single scan rather than six scans with four sensors, a special software application was written to "cut and splice" the data. The cutting location was aided by fine wires fixed on the plate surface that demarked the scan zone by narrow pulses in the data. Processed data were also rearranged and grouped by type into a new data file in which, for example, all the $10-\mathrm{kHz}$ magnitude data were together. This final spliced data file then looked like it was from a tool with four kinds of collocated NLH sensors - $10-\mathrm{kHz}$ magnitude, $30 \mathrm{kHz} \mathrm{I}, 30 \mathrm{kHz}$ Q, and 20-kHz magnitude. For each of these types, there were 24 channels [spaced by 0.5 inch $(0.12 \mathrm{~mm})$ ] in Y and sampled every 0.0048 inch $(0.12 \mathrm{~mm})$ in X. For this new file, the four types of NLH sensors could then be processed and displayed simultaneously by Tuboscope's LinaView ${ }^{\mathrm{TM}}$ commercial display software.

Before final display, offsets (from the detectors, level shifting, or ADCs) were subtracted from the channels, and channels were gain-equalized by multiplicative gain constants. The offsets and gains were obtained from a number of separate calibration runs. The offsets were the acquired amplitudes from a run with the sensor receiver coils disconnected. The gain constants were from a run with the sensors in air. The gains computed are such that the air responses of all these sensors are equal and matched to those of sensor 1.

Previous scan results done by SwRI are shown as contour plots in Figure $25(30-\mathrm{kHz}$ magnitude) and Figure $26(30-\mathrm{kHz}$ phase). These were taken by SwRI using the lock-in amplifier as described previously. These data were acquired from a probe with a two-axis gimbal, which enabled the sensor to stay in contact with the plate. Note that the original SwRI data in these figures have been resampled in the $\mathrm{Y}$ direction to $0.5 \mathrm{inch}(12 \mathrm{~mm})$ from 0.04 inch $(1 \mathrm{~mm})$ to 


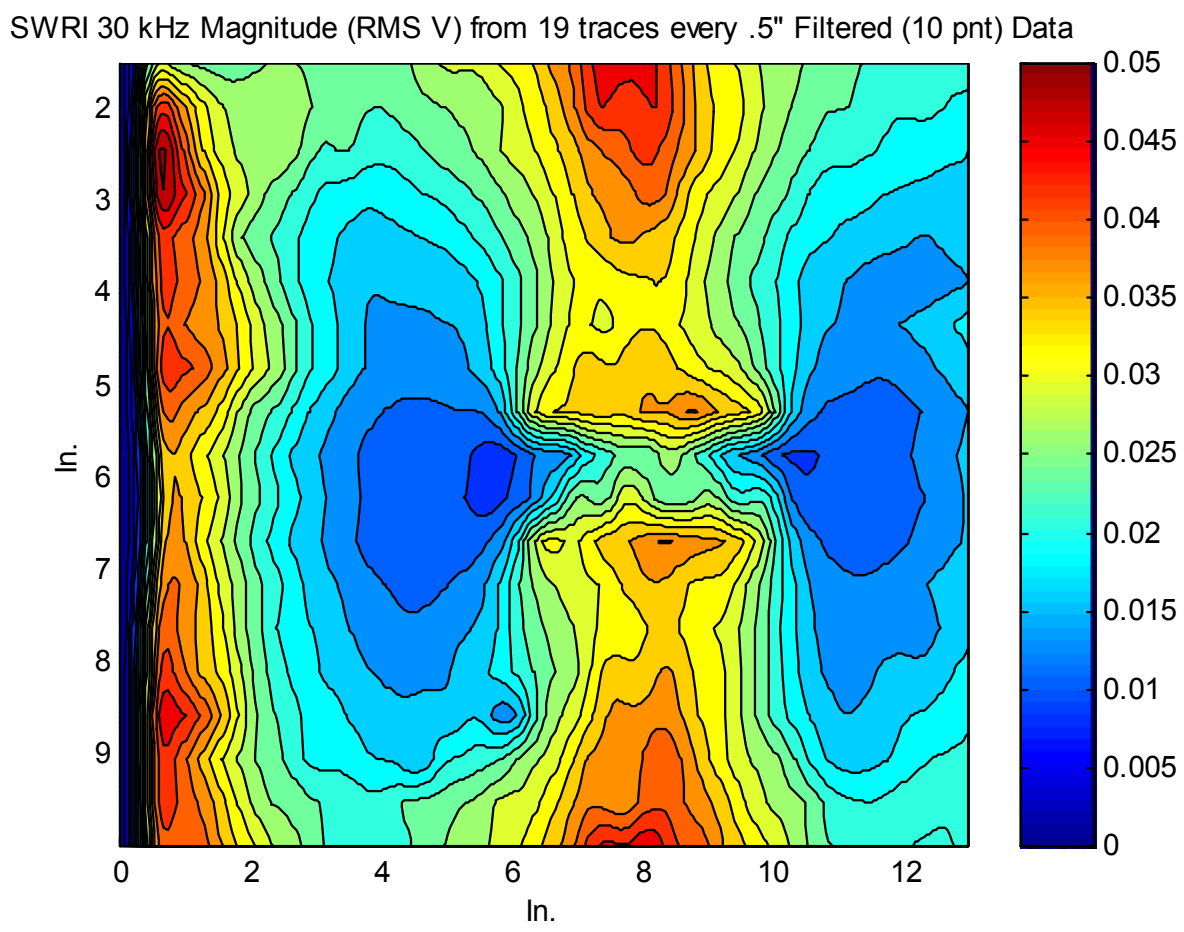

Figure 25. Previous SwRI scan results 30-kHz magnitude [Y traces every 0.5 inch $(12 \mathrm{~mm})$ ]

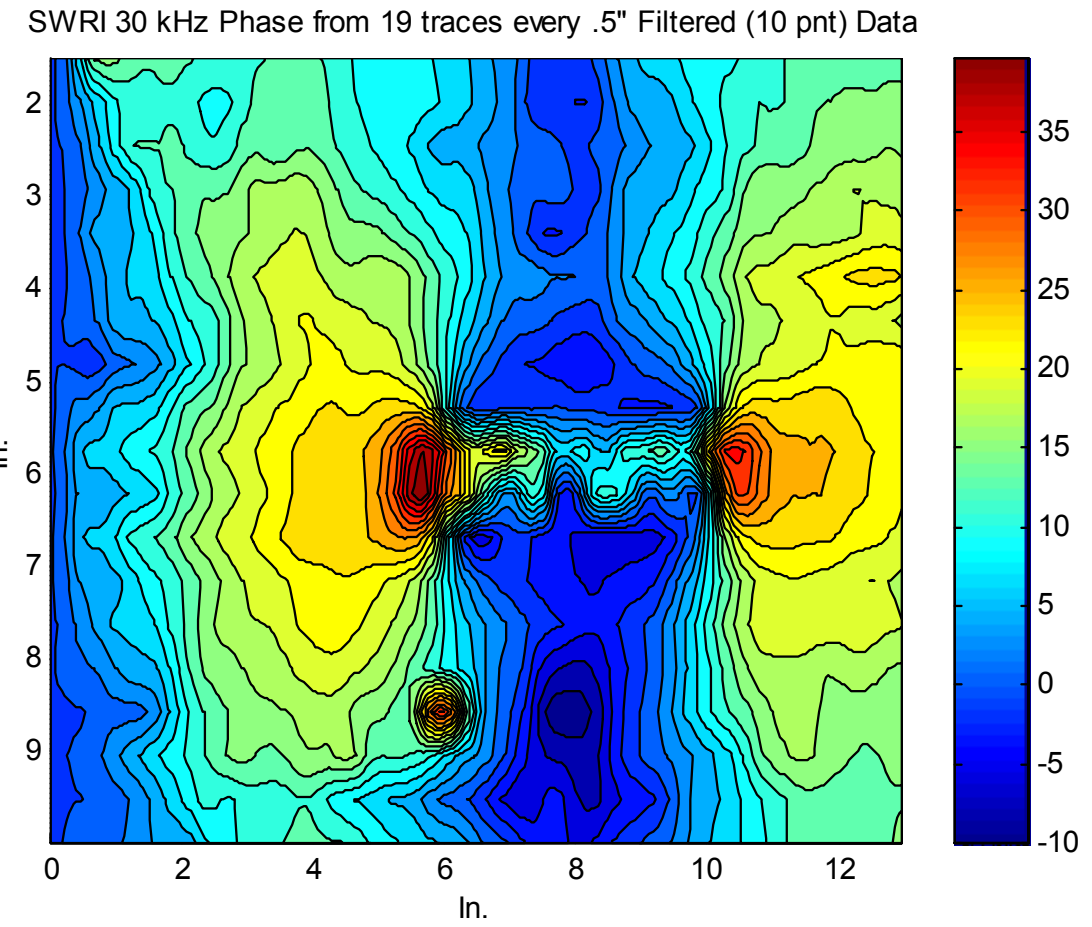

Figure 26. Previous SwRI scan results 30-kHz phase [Y traces every 0.5 inch $(12 \mathrm{~mm})$ ] 


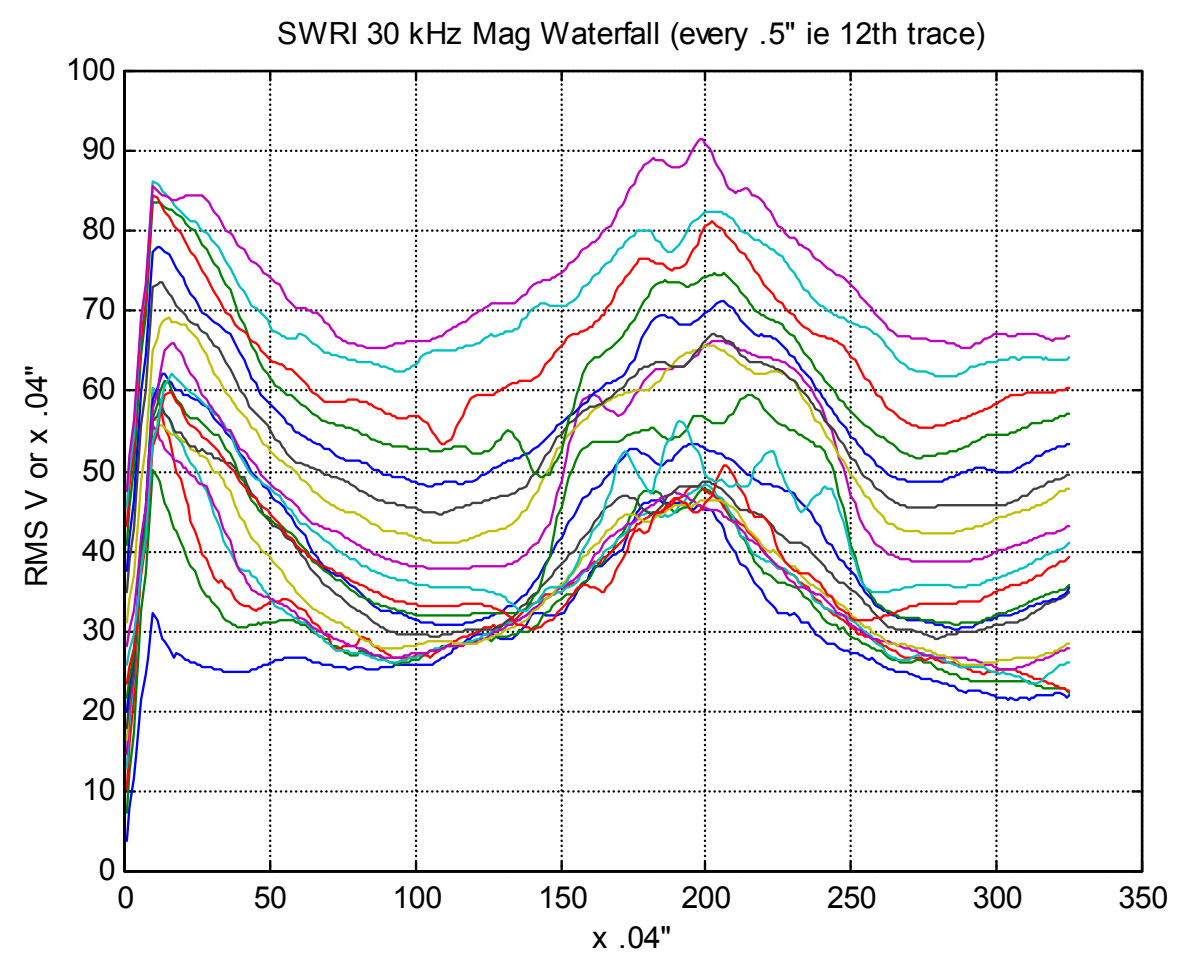

Figure 27. Previous SwRI scan results: Waterfall plot of 30-kHz magnitude [Y traces every 0.5 inch $(12 \mathrm{~mm})$ ]

give it similar sampling to the Tuboscope data. Also, the Y-axis in these figures goes from 1.5 inch $(38 \mathrm{~m})$ to about 10 inches $(250 \mathrm{~mm})$ to correspond to the scan of the Tuboscope prototype, which covered more of the plate. Figure 27 shows the magnitude traces every 0.5 inch $(12 \mathrm{~mm})$, corresponding to the contour plots.

\subsection{Prototype Data Analysis}

The spliced, calibrated $30-\mathrm{kHz}$ prototype magnitude data displayed with LinaView ${ }^{\mathrm{TM}}$ is shown in Figure 28. The contour plot used smoothing and scaling to best display contrasts in the data.

Like the SwRI 30-kHz magnitude contours (Figure 25), the prototype (Figure 28) has high spots and a channel near the center, where the plate bulges. Figure 28 also shows two peaks near the left side of the plate [at $\mathrm{Y}=2.5$ and 9.5 inches $(63.5$ and $240 \mathrm{~mm})$ ]. In general, these features in Figure 28 are less pronounced in that the channel is narrower and the peaks are smaller. Also, the peaks of Figure 28 are not as symmetrical.

Two features missing in the prototype data are broad peaks that intersect the top and bottom edges at $(\mathrm{X}, \mathrm{Y})=\left(8^{\prime \prime}, 1.5^{\prime \prime}\right)$ and $\left(8^{\prime \prime}, 10^{\prime \prime}\right)$. Another difference is the lack of wide troughs centered in $Y=6 "$ at about $X=5 "$ and $X=11 "$. These are just to the left and right of the bulge.

More prototype data, this time for 10-kHz magnitude, are presented in Figure 29. This shows a high amplitude band from $\mathrm{Y}=5.5^{\prime \prime}$ to 9 ". This high-amplitude band shows there is more $10-\mathrm{kHz}$ drive on the plate in this band. It also has a deep trough at $(\mathrm{X}, \mathrm{Y})=\left(5.5^{\prime \prime}, 4 "\right)$, indicating less drive. 


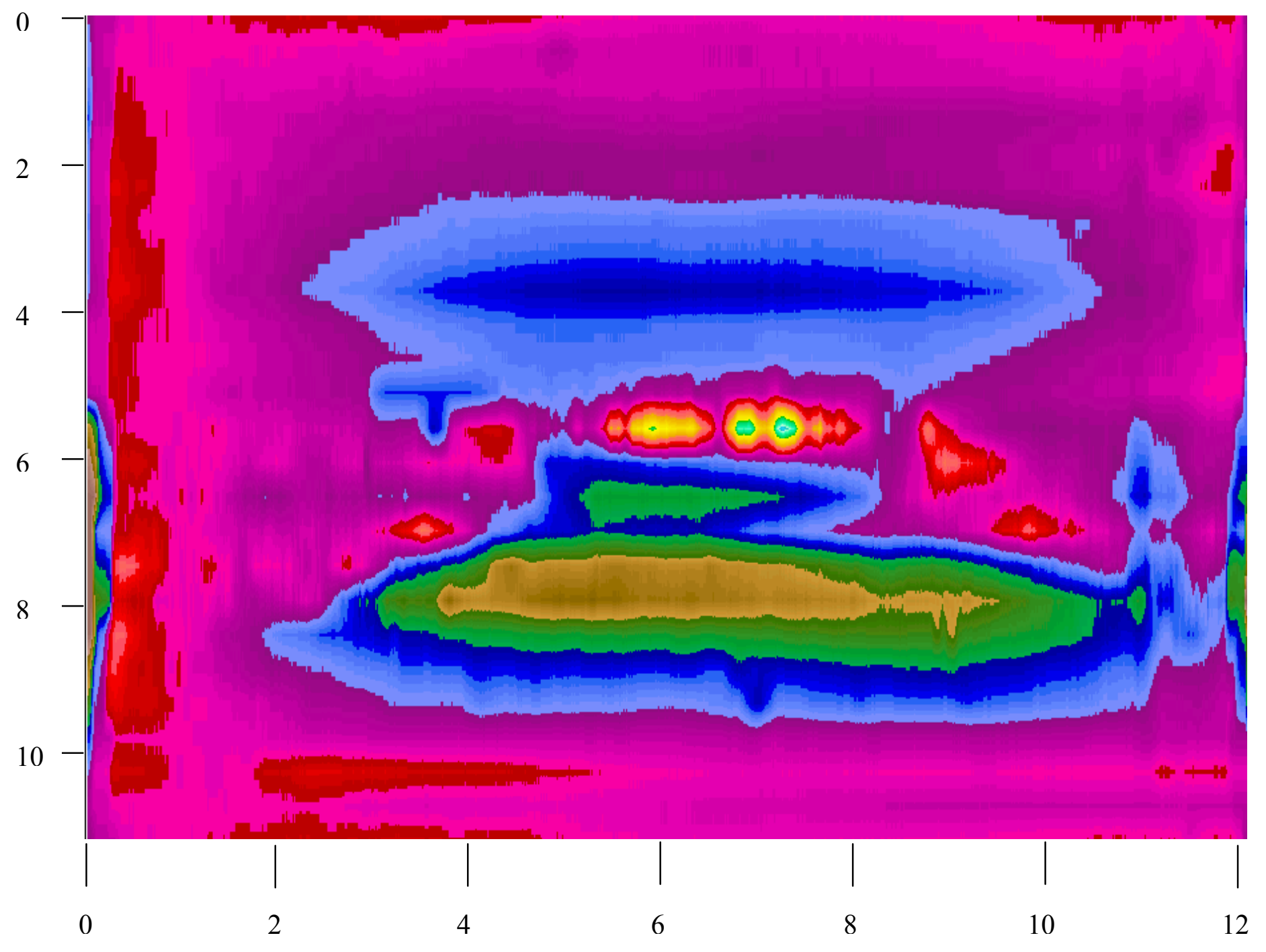

Figure 28. Tuboscope LinaView ${ }^{\mathrm{TM}}$ contour scan: $30-\mathrm{kHz}$ magnitude (scales in inches) 


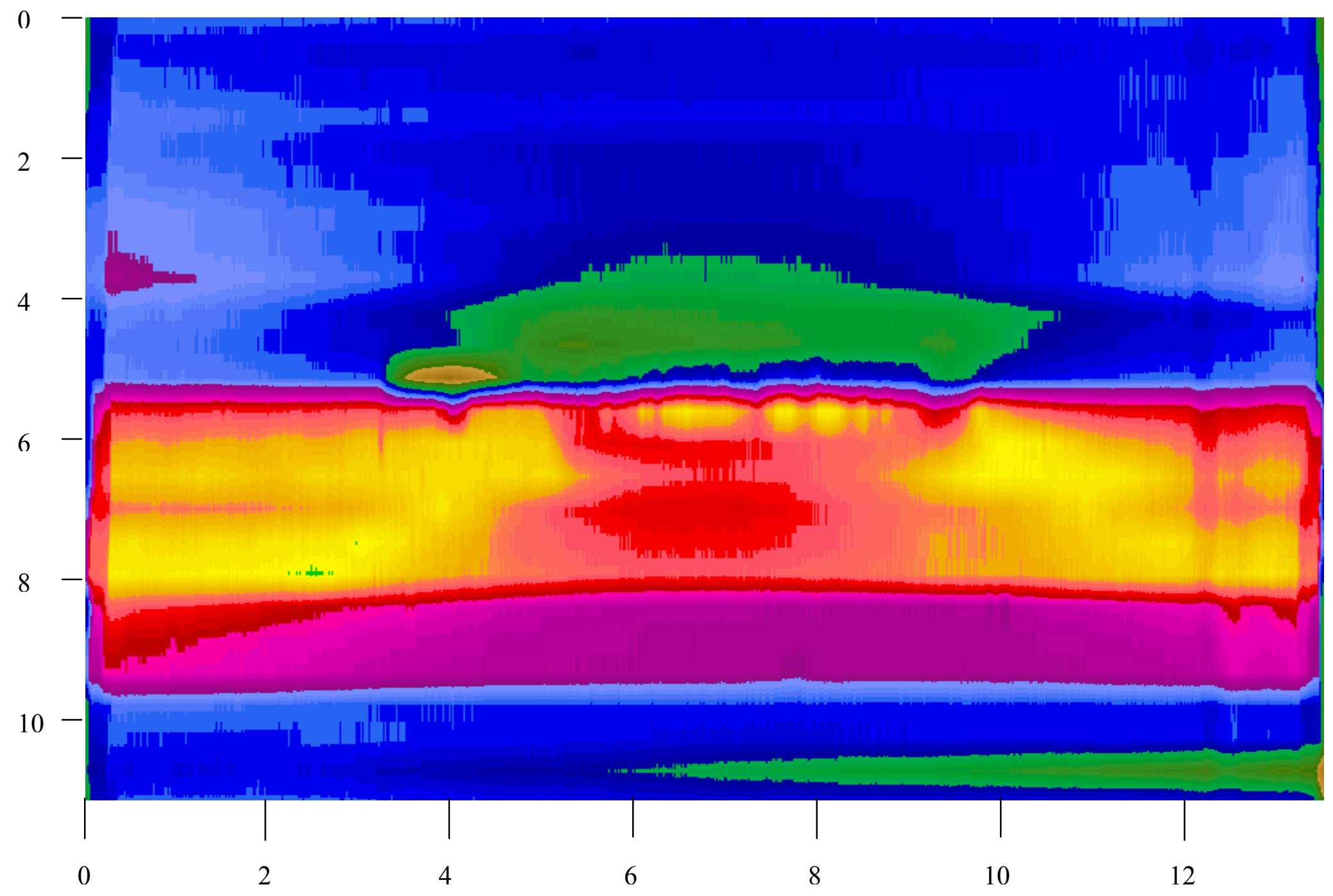

Figure 29. Tuboscope LinaView ${ }^{\mathrm{TM}}$ contour scan: 10-kHz magnitude (scales in inches) 
The $10-\mathrm{kHz}$ magnitude plot gives some insight about the $30-\mathrm{kHz}$ magnitude. The $10-\mathrm{kHz}$ drive changes would directly affect the $30-\mathrm{kHz}$ magnitude and cause the high band and hole in it. These effects then reduce the symmetry and wipe out the troughs that should occur to the left and right of the bulge.

The $10 \mathrm{kHz}$ also shows reduced amplitude and drive at around $\mathrm{X}=6$ " from $\mathrm{Y}=2$ " to 4.5 ". This area of reduced drive kills any possible response to the peak at the bottom edge of the plate (around $\mathrm{X}=8^{\prime \prime}, \mathrm{Y}=1.5^{\prime}$ ).

Why the $10 \mathrm{kHz}$ increases and decreases is not exactly known at this time. However, observations of the probe indicated that probe angle and pressure on the probe affected amplitude. Also, as the probe moved in the high- and low-amplitude areas, the support arm could vary the probe contact angle and pressure. It was also seen that the both $10-$ and $30-\mathrm{kHz}$ amplitudes were very sensitive to liftoff. This sensitivity would be worsened by the single degree of freedom in the prototype sensor. This could have distorted results on the flanks of the bulge. 


\section{CONCLUSION}

The plate with a stress-rising defect was scanned by Tuboscope using a relatively standard, robust, sensor-mounting assembly with circuits connected to a high-performance commercial recorder and with electronics for detection that could easily be integrated with it. These data were processed and displayed by Tuboscope's standard commercial software.

This plate was previously scanned by SwRI with a two-axis gimbaled probe and laboratory equipment. Note that the sensor orientation was the same as that for the prototype scans, aligned with the long axis of the plate. Comparison of the $30-\mathrm{kHz}$ magnitude data showed the same major features, which is definitely a good start on commercialization. However, as noted above, some of the minor features were missing in the prototype data.

Differences in the SwRI and Tuboscope $30 \mathrm{kHz}$ could be caused by differences in $10-\mathrm{kHz}$ drive level, liftoff that affected both $10 \mathrm{kHz}$ and $30 \mathrm{kHz}$, a need for a different calibration, a difference between the SwRI and Tuboscope prototype sensor, or some unseen difference between the lockin amplifier and prototype detection electronics. A possible next step to advance commercialization would be to follow up on these issues. This should include additional plate scans with only one sensor as a check on calibration, a change in the scan, or arm support to eliminate sensor contact issues. By using the SwRI sensor with the prototype electronics, it could be determined whether the differences lie in the sensor or the electronics.

It should also be noted that this system was evaluated by detection of mechanical damage from a single sample. Deploying this methodology commercially would first entail performing similar experiments with a large number of defects of varying severity. The next step would be the development of grading algorithms to characterize the severity of the mechanical damage. Earlier work by SwRI under DOT funding produced significant progress toward development of mechanical damage grading algorithms. These algorithms would serve as a starting point for any new characterization work. 


\section{REFERENCES}

1. Leis, B. N., T. A. Bubenik, R. B. Francini, J. B. Nestleroth, and R. J. Davis, "Recent Developments in Voiding, Detecting, and Assessing the Severity of Mechanical Damage," The Pipeline Pigging, Integrity Assessment, and Repair Conference, February 1-2. 2000.

2. Chell, G. G., Y. D. Lee, A. E. Crouch, V. Aaron, C. J. Kuhlman, and R. W. Warke, "Assessment Criteria for Mechanical Damage in Gas Transmission Pipelines," Final Report GRI-00/0222, GRI Contract No. 6026, Southwest Research Institute: San Antonio, Texas (December 2000).

3. Crouch, A. E., "Development of Nonlinear Harmonic Sensors for Detection of Mechanical Damage," National Gas Technologies II, February 8-11, 2004, Phoenix, Arizona (DOE Contract No. DE-FC26-01NT41156).

4. Crouch, A. E., and G. G. Chell, "New NDE Technology Detects, Characterizes Dent, Gouge Defects," Oil \& Gas Journal, August 4, 2003, pp. 52-58. 